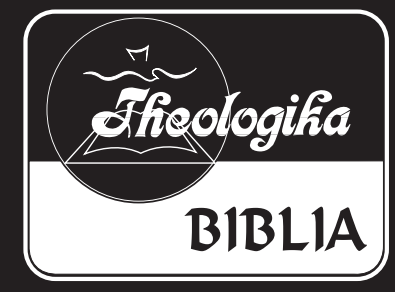

\title{
El motivo de la creación en la literatura profétioa veterotestamentaria: un estudio intertextual
}




\section{RESUMEN}

“El tema de la creación en la literatura profética veterotestamentaria: un estudio intertextual" - La creación es un tema muy prominente en la literatura profética del Antiguo Testamento. Pese a que la erudición bíblica a menudo ha descuidado e incluso ha buscado relegarla a un nivel más bien secundario de subtítulo dentro de las secciones de la soteriología, pacto, Trinidad o cualquier otra sección de importancia, la creación mantiene su estatus destacado en la literatura bíblica incluyendo los profetas veterotestamentarios. El autor tras establecer un patrón cronológico adecuado, demuestra que en todos los libros proféticos existen indicadores intertextuales explícitos e implícitos que señalan a la creación en los profetas, indicando que todos ellos vieron a la creación como un hecho literal e histórico, puesto que la referencia al relato de la creación la hacen indiscriminadamente tal como se presenta en Gén 1-2.

\section{SUMMARY}

"Creation in the Prophetic Literature of the Old Testament: an Intertextual Study"-Creation is a very prominent theme in Old Testament prophetic literature. Despite the fact that biblical scholarship has often been neglected and even sought to relegate to a secondary level rather than subtitle within the sections of soteriology, covenant, Trinity or any other important section, creation maintains its relevant status within the Biblical literature including the Old Testament prophets. The author, after establishing an appropriate chronological framework against which the usage of creation texts is pitched, he shows that in all the prophetic books appear implicit and explicit intertextual markers pointing to creation as being historical, since the reference to the story of creation makes it indiscriminately as presented in Gen 1 - 2. 


\section{EL MOTIVO DE LA CREACIÓN EN LA LITERATU- RA PROFÉTICA VETEROTESTAMENTARIA: UN ESTUDIO INTERTEXTUAL}

\section{Introducción}

El motivo de la creación en la teología del Antiguo Testamento en su historia más reciente ha sido descuidado y a menudo ésta ha sido relegada hasta casi el nivel de un subtítulo dentro de las secciones de la soteriología, pacto, Trinidad o cualquier otra sección relevante posible: "Sin embargo, la creación hasta hoy día ha sido uno de los 'hijos adoptivos proverbiales' en la disciplina reciente del Antiguo Testamento". ${ }^{1}$ En tanto que Rendtorff solo diagnostica el problema, Brueggemann buscando una justificación, refiere la responsabilidad para la posición periférica de la creación en la teología a la dicotomía entre la religión cananea y la fe israelita, o la historia y el mito, que encontró su camino dentro de la teología bíblica durante los inicios del último siglos mediante eruditos como Gerhard von Rad en Europa quien sugirió que la creación era sub-sirviente a la salvación ${ }^{2}$ o Ernst Wright

${ }^{1}$ Rolf Rendtorff, "Some Reflextions as a Topic of Old Testament Theology", en Eugen Ulrich, John W. Wright, Robert P. Carroll, and Philip R. Davies, eds., Priests, Prophets and Scribes. Essays on the Formation and Heritage of the Second Temple Judaism in Honour of Joseph Blenkinsopp - JSOTSS 149 (Sheffield: SeffieldAcaemic Press, 1992), 204-212.

${ }^{2}$ "Nuestra tesis principal era que en la creencia Jehovística genuina la doctrina de la creación nunca llegó a la estatura de una doctrina 
en USA quien sostuvo que "Israel se interesaba muy poco en la naturaleza". 3

Un considerable número de teólogos se alinearon con el paradigma creado por von $\operatorname{Rad}^{4}$ y reconocieron la prominencia de la creación en el pensamiento teológico del Antiguo Testamento, ambos en términos de posición y contenido.

Claus Westermann en su obra Génesis 1-11 pone a la Creación en la historia a través de su expresión en el mito y el ritual. Así es el evento primeval y las historias hablaron acerca de ella y la establecieron como parte de las tradiciones universales de la humanidad. Los autores bíblicos —según Westermann el autor Jehovista y

relevante e independiente. La encontramos, invariablemente relacionada a consideraciones soteriológicas", Gerhard von Rad, "The Theological Problem of the O.T. Doctrine of Creation", en Bernhard B. Anderson, ed., Creation in the Old Testament - Issues in Theology and Religion 6 (Philadelphia and London: Fortress and SPCK, 1984), 62. El artículo fue publicado originalmente en 1936.

${ }^{3}$ Ernest Wright, The Old Testament Against its Environment (London: SCM, 1950), 71. Von Rad vio la creación como una adición muy tardía a la construcción teológica del Antiguo Testamento. Brueggemann sostiene que las conclusiones de von Rad estaban enmarcadas por el contexto sociocultural de la década de los años de 1930 con la lucha entre la iglesia alemana y el Socialismo Nacional que promulgó una religión de "sangre y suelo" que se inclinó hacia la religión de la fertilidad cananea. Brueggemann concluye: "La obra de Gerhard von Rad y Ernest Wright, tomaron, avanzaron e hicieron eco de numerosos eruditos, articularon uno u otro radical de historia versus naturaleza, monoteísmo versus politeísmo, y ética versus categorías cúlticas", Walter Brueggemann, "The Loss and Recovery of Creation in Old Testament Theology", Theology Today, 53 (1996) 79.

4"La erudición veterotestamentaria es casi unánime con respecto a la fe en la creación en el antiguo Israel como cronológicamente tardía y teológicamente secundaria". Hans Heinrich Schmid, "Creation, Righteousness, and Salvation, 'Creation Theology' as the Broad Horizon of Biblical Theology", en Bernhard W. Anderson, ed., Creation in Old Testament - Issues in Theology and Religion 6 (Philadelphian and London: SPK, 1984) 103. 
el sacerdotal - adaptaron esas historias teológicamente para Israel y las identificaron como parte de la obra de bendición de Dios la cual para Westermann "en realidad significa el poder de la fertilidad". ${ }^{5}$

En contraste directo e intencional con von Rad la doctrina ha sido descrita por Hans Heinrich Schmid como el horizonte de la teología bíblica. Él relaciona la creación al orden del mundo y comparándola con las creencias de la creación en otras culturas del ACO él llega a la conclusión de que la historia es la realización de este orden. ${ }^{6}$ "Únicamente dentro de este horizonte Israel podía entender sus experiencias especiales con Dios en la historia". ${ }^{7}$ Uno pondera si Schmid no está cometiendo el error de los primeros teólogos bíblicos al buscar el Mitte del Antiguo Testamento y localizarlo en la Creación. ${ }^{8}$

${ }^{5}$ Claus Westermann, "Creation and History in the Old Testament", en Vilmos Vajta, ed., The Gospel and Human Destiny (Minneapolis: Augsburg, 1971), 32.

${ }^{6}$ Schmid llega a esa conclusión haciendo un paralelo entre el hebreo צד, "justicia" y el egipcio ma-at, "orden mundial". Para una crítica de suposición ver Stefan Paas, Creation and Judgement: Creation Texts in Some Eighth Century Prophets - Oudtestamentische Stüdien 47 (Leiden-Boston: Brill, 2003) 10-14.

${ }^{7}$ Ibíd.

${ }^{8}$ Ver, por ejemplo, Smend que considera la doctrina de la elección como troncal en la Teología del Antiguo Testamento. Rudolf Smend, Die Mitte des Alten Testaments: Gesamelten Studiem, Bd. 1- (München: Chr. Verlag, 1986). Teologías del Antiguo Testamento recientes han abandonado esta postura. Hasel comenta: "Una teología del Antiguo Testamento que reconoce a Dios como el centro unificador y dinámico provee la posibilidad de describir las ricas y variadas así como presentar los temas longitudinales, así como los motivos e ideas. Al afirmar a Dios como el centro unificador y dinámico del Antiguo Testamento también afirmamos que este centro no puede ser forzado dentro de un principio organizador estático sobre la base de que una teología del Antiguo Testamento puede ser construida". Gerhard F. Hasel, Old Testament Theology: Basic Issues in a Current Debate (Grand Rapids: Eerdmans, 1987) 142. 
Sin embargo, pareciera que en la mayoría de los casos, la fechación de los textos descansa en el fondo del asunto como dónde poner la creación dentro del cuadro de la teología del Antiguo Testamento. En tanto que la Biblia comienza con la creación, la mayoría de las teologías bíblicas no lo hacen, ya que los tratados críticos tradicionales a los textos del Antiguo Testamento no permiten una fechación temprana del Urgeschichte (Gén 1-11). ${ }^{9} \mathrm{La}$ mayoría de estos estudios, incluyendo el de von Rad, han tomado más bien a Isaías 40-55, el llamado Deutero-Isaías, fechado por el criticismo literario como perteneciente a tiempos postexílicos, como un paradigma cronológico seguro para la creación en el Antiguo Testamento contra el cual otros textos, entre ellos Génesis 1-3 han sido puestos como marcadores. ${ }^{10}$ Esto lleva inevitablemente a la conclusión de que la creación es una adición posterior al pensamiento teológico del Antiguo Testamento. ${ }^{11}$ Implícito en esta concepción está el peligro del razonamiento circular,

9 Blenkinsopp resume el concepto tradicional de la crítica de fuentes con respecto a Gén 1-11: "Según los críticos documentarios esto [Gén 1-2] es el primer párrafo del documento P. Con muy pocas excepciones . . . estos críticos han leído la primera historia de la humanidad [Gén 1-11] como conflación de una fuente primitiva J y una posterior P . . .", Joseph Blenkinsopp, The Pentateuch: An Introduction to the First Five Books of the Bible - Anchor Bible Reference Library (New York: Doubleday, 1992) 60.

${ }^{10}$ Paas comenta: “La razón por la cual una pesquisa sobre la creación en el Antiguo Testamento a menudo comienza con Deutero-Isaías es obvia. Con respecto a la fechación de los Salmos e incluso las historias de los orígenes hay mucho menos concordancia", Paas, Creation and Judgement, 14.

${ }^{11}$ Con referencia al artículo que von Rad escribiera en 1936, Brueggemann comenta: "Fue en este artículo . . que von Rad aseveró que 'la doctrina de la creación' era periferal al Antiguo Testamento, y que el Antiguo Testamento no estuvo, al menos hasta muy tarde, para nada interesado en la creación”, Brueggemann, “The Loss and Recovery of Creation”, 178, 
puesto que los textos de la creación están siendo fechados sobre la base de paradigmas religiosos históricos como tardíos y están también siendo usados del mismo modo para fechar otros textos sobre la creación:

Obviamente es algo así como paralizante el percatarse que nosotros formamos un cuadro de la historia religiosa de Israel, en parte basados sobre ciertos textos que, a su vez, con la ayuda del cuadro obtenido por la pesquisa histórica, hemos juzgado subsecuentemente con respecto a la 'autenticidad' y la verdad histórica. ${ }^{12}$

Reconociendo los resultados insatisfactorios de semejante esquema de datación, que es luego informada por una escuela de pensamiento particular con respecto a la historia religiosa israelita, ${ }^{13}$ un concepto sobre el tópico de la creación en el Antiguo Testamento debiera de partir de una lectura contextual de los textos en cuestión en los cuerpos de diferentes textos de literatura del Antiguo Testamento.

La literatura profética del Antiguo Testamento proporciona un excelente material para semejante lectura ya que la naturaleza implícita de la profecía en el Antiguo Testamento es de naturaleza re-formativa, i.e., refiriéndose hacia atrás en los hechos históricos de Jehová realizados en el pasado (creación, éxodo, conquista, etc.) y por lo tanto motivando un retorno hacia él en el respectivo presente. En tanto que hay estudios que han tocado sobre el asunto de la creación en libros proféticos

${ }^{12}$ Paas, Creation \& Judgement, 29.

${ }^{13 “}$ Pero en la actualidad el problema de la fechación de los textos así como la edad de las tradiciones sobre la creación en Israel son más controversiales que nunca antes", Rendtorff, "Some Reflections on Creation", 208. 


\section{individuales, ${ }^{14}$ hay necesidad de un tratamiento más sin- tético sobre el asunto en cuestión. ${ }^{15}$ El presente estudio}

${ }^{14}$ Por ejemplo Walter Brueggemann, "Jeremiah: Creatio in Extremis", en William P. Brown and S. Dean McBride Jr., eds., God Who Creates: Essays in Honor of W. Sibley Towner (Grand Rapids: Eerdmans, 2000) 152-170; Richard J. Clifford, "The Unity of the Book of Isaiah and its Cosmogonic Language", Catholic Biblical Quarterly 55 (1993) 1-17; Stephen L. Cook, "Creation Archetypes and Mythogems in Ezekiel: Significance and Theological Ramifications", en SBL Seminar Papers , 1999 (Society of Biblical Literature Seminar Papers 38 ; Atlanta, Scholars Press, 1999), 123-146; Andrew A. da Silva, "Die funksie van die skeppingstradisie in die boek Jeremiah", Hervormde Theologiese Studies 47:4 (1991) 920-929; Michael Deroche, "Zephania I 2-3: The Sweeping of Creation", VetusTestamentum 30:1 (1980) 104-109; idem, "The Reversal of Creation in Osea", VetusTestamentum 31:4 (1981) 400-409; Michael Fishbane, "Jeremiah IV 23-26 and Job III 3-13: A Recovered Use of the Creational Pattern”, VetusTestamentum 21:2 (1971) 151-167; Julie Galambush, "Castles in the Air: Creation as Property in Ezekiel", en SBL Seminar Papers, 1999 (Society of Biblical Literature Seminar Papers 38 ; Atlanta, Scholars Press, 1999), 147-172; Thomas W. Mann, "Stars, Sprouts and Men: The Creator Redeemer in Second Isaiah", en William P. Brown, en S. Dean McBride Jr., God Who Creates: Essays in Honor of W. Sibley Towner (Grand Rapids: Eerdmans, 2000) 135-151; David L. Peteresen, "Creation in Ezekiel: Methodological Perspectives and Theological Prospects", en SBL Seminar Papers , 1999 (Society of Biblical Literature Seminar Papers 38 ; Atlanta, Scholars Press, 1999), 490-526; Gerhard Pfeifer, "Yahwe als Schöpfer der Welt und Herr ihrer Mächte in der Verkündigung des Propheten Amos", VetusTestamentum 41:4 (1991) 475-481; Dominic Rudman, "Creation and Fall in Jeremiah X 12-16", Vetus Testamentum 48.1 (1998) 63-73; Gene M. Tucker, "The Peaceable Kingdom and a Covenant with the Wild Animals", en William P. Brown, en S. Dean McBride Jr., God Who Creates: Essays in Honor of W. Sibley Towner (Grand Rapids: Eerdmans, 2000) 215-225; Steven Tuell, "The Rivers of Paradise: Ezekiel 47:1-12 and Genesis 2:10-14", en William P. Brown, en S. Dean McBride Jr., God Who Creates: Essays in Honor of W. Sibley Towner (Grand Rapids: Eerdmans, 2000) 171-189; y Robert R. Wilson, "Ceration and New Creation: The Role of Creation Imagery in the Book of Daniel", en William P. Brown, en S. Dean McBride Jr., God Who Creates: Essays in Honor of W. Sibley Towner (Grand Rapids: Eerdmans, 2000) 190-203.

${ }^{15}$ Las excepciones son: A. Bronders Hendrick, De Scheppingstraditiebij depropheten (Amsterdam: H. J. Paris, 1945); Wolfram Hermann, "Wan wurden Jahwe zum Schöpfer der Welt", Ugarit-Forschungen 23 (1992) 165-180; David 
proporcionará un repaso al motivo de la creación,, ${ }^{16}$ en la literatura profética del Antiguo Testamento, i.e. en los libros de Isaías, Jeremías, Ezequiel, el libro de los Doce, y Daniel, aunque el orden de presentación será más bien cronológico que canónico. Este repaso podría proporcionar alguna aclaración sobre la cuestión concerniente a si los profetas del Antiguo Testamento basaron su entendimiento acerca de la creación en el modelo presentado en Génesis 1-3 o si su cosmología permitió otros modelos de creación.

\section{Cuestiones metodológicas}

Hay dos puntos que necesitan ser atendidos antes de evaluar la evidencia de la creación en los profetas del Antiguo Testamento. El primero es el asunto de la intertextualidad, basado en la mención hecha antes de que mucho del mensaje de los profetas, es intrínsecamente

L. Petersen, "The Book of Creation in the Book of the Twelve", en William P. Brown, en S. Dean McBride Jr., God Who Creates: Essays in Honor of W. Sibley Towner (Grand Rapids: Eerdmans, 2000) 204-214; Hans J. Zobel, “Das Schöpfungs handeln Jahwes in Zeugnis der Propheten", en Jutta Hermann and Hans J. Zobel, eds., Altentestamenticher Glaube und biblische Theologie: Fetschrift für Horst Dietrich Preusszum 65. Geburstag (Stuttgart: Kohlhammer, 1992) 191-200; y más recientemente, Paas, Creation and Judgement. Este estudio es hecho en base a la tesis doctoral de Paas que originalmente fue publicada en 1998 y actualizada en el 2004. El autor estudia los motivos de la creación en los profetas del siglo VIII A.C. (Amós, Oseas e Isaías), dejando a un lado a Miqueas, pues según Paas, este profeta carece de menciones a la creación (15). La fuerza del estudio de Paas reside en su aproximación metodológica que es reflejada de algún modo en el presente estudio.

${ }^{16}$ Las referencias a la creación pueden aparecer en una variedad de formas dentro de la literatura profética del Antiguo Testamento. Para una delimitación de los marcadores de la creación en el texto, cf. nuestra discusión más abajo en el 2.2. 
evocativo de textos más tempranos, creando puntos de referencia a eventos en el curso de la historia de Israel, pero al mismo tiempo pero al mismo tiempo aplicándolos a su contexto actualizado. ${ }^{17} \mathrm{El}$ segundo punto surge de algún modo del primero y se refiere a la cuestión de cómo uno puede identificar referencia a la creación en la literatura profética del Antiguo Testamento.

\subsection{Intertextualidad}

La intertextualidad ha llegado a ser recientemente el foco céntrico en la erudición bíblica aunque más bien parece ser elusiva cuando trata de ser sujeta a algunos intentos que buscan una definición del concepto. ${ }^{18}$ Una

${ }^{17}$ Ver por ejemplo el anuncio de Ezequiel durante el exilio babilónico que es reminiscente de la creación, sin embargo, en el contexto de restauración: "Multiplicaré sobre vosotros hombres y ganado, y serán multiplicados y crecerán; y os haré morar como solíais antiguamente; y os haré mayor bien que en vuestros principios; y sabréis que yo soy Jehová" (Eze 36:11).

${ }^{18} \mathrm{La}$ introducción del término se ha atribuido a Julia Kristeva, Desire in Language: A Semiotic Approach to Literature and Art (New York: Columbia University Press, 1980). Algunas de las contribuciones sobre la teoría intertextual en los estudios bíblicos durante los últimos años incluyen: Brevard S. Childs, "Critique of Recent Intertextual Canonical Interpretation", Zeitschrift für die Alttentestamentliche Wissenchaft 115:2 (2003) 173-184; Paul R. Noble, "Esau, Tamar and Joseph: Criteria for Identifying Inner-Biblical Alussions", Vetus Testamentum 52:2 (2002) 219-252; Gary E. Schnittjer, "The Narrative Multiverse Within the Universe of the Bible: the Question of 'Borderlines' and 'Intertextuality', Westminster Theological Journal 64:2 (2002) 231-252, Robert W. Wall, "The Intertextuality of Scripture: The Example of Rahab (Sant 2:25)", en Peter W. Flint, ed., The Bible at Qumran: Text, Shape and Interpretation (Grand Rapids: Eerdmans, 2001) 217-236; Richard L. Schultz, "The Ties that Binds: Intertextuality and the Study of the Old Testament in the New Testament", Society of Biblical Literature 2001 Seminar Papers Society of Biblical Literature Seminar Paper 40 (Atlanta: Society of Biblical 
cantidad de enfoques han sido resumidos bajo este término como paraguas, pero en realidad yo definiría la intertextualidad como referencias entre textos que pueden ocurrir sobre múltiples niveles, ${ }^{19}$ en tanto que sus límites son a menudo determinados por el concepto de composición de la Escritura que tenga el escritor que la está empleando. Lo que la intertextualidad hace con los textos es unir a estos en un sistema de tal modo que crea nuevos contextos $y$, de esta manera, nuevos significados de textos antiguos. ${ }^{20} \mathrm{La}$ intertextualidad

Literature, 2001), 39-57; Gerson Hepner, "Verbal Resonance in the Bible and Intertextuality", Journal for the Study of the Old Testament 96 (2001) 3-27; Craig C. Broyles, "Tradition, Intertextuality and Canon", en Craig C. Broyles, ed., Interpreting the Old Testament: A Guide for Exegesis (Grand Rapids: Baker Academic, 2001) 157-175; Steve Moyise, "Intertextuality and the Study of the Old Testament in the New Testament", en Steve Moyise, ed., The Old Testament in the New Testament. Essays in Honour of J, L. North - Journal for the Study of the New Testament Supplement Series 189 (Sheffield: Sheffield Academic Press, 2000) 14-41; John Barton, "Intertextuality and the 'Final Form' of the Text", en André Lemaire and M. Saebø eds., Congress Volume Oslo 1988 - Supplements to Vetus Testamentum 80 (Leiden, Boston, Köln: Brill, 2000) 33-37; Patricia Tull, "Intertextuality and the Hebrew Scriptures", Currents in Research: Biblical Studies 8 (2000) 59-90.

${ }^{19}$ Vea debajo en 2.2

${ }^{20}$ Nielsen hace una diferencia entre tres frases para la lectura intertextual: (1) la intención del autor; (2) las intenciones editoriales y canónicas; y (3) las tradiciones post-bíblicas y la respuesta del lector. Kirsten Nielsen, "Intertextuality and the Hebrew Bible", en André Lemaire and M. Saebø eds., Congress Volume Oslo 1988 - Supplements to Vetus Testamentum 80 (Leiden, Boston, Köln: Brill, 2000) 18-19. Sin embargo para Nielsen parece casi imposible reconstruir la segunda frase en tanto que otros eruditos como Labahn reconocen la dimensión cronológica bíblica-interna de la intertextualidad. Antje Labahn, "Metaphor and Intertextuality: 'Daughter of Zion' As a Text Case: Response to Kisrten Nielsen "From Oracles to Canon" - and the role of Metaphor", Scandinavian Journal of the Old Testament 17:1 (2003) 51. 
también pone varios textos sobre una, a veces, línea de tiempo complicado y de esta manera genera consideraciones cronológicas que han estado desenfocadas en gran medida de los estudios bíblicos del criticismo literario en boga. ${ }^{21}$

Al aplicar a los profetas del Antiguo Testamento me gustaría sugerir la siguiente línea de tiempo que servirá como el marco cronológico contra el cual el uso de los textos sobre la creación en los profetas tiene que ser montado. ${ }^{22}$
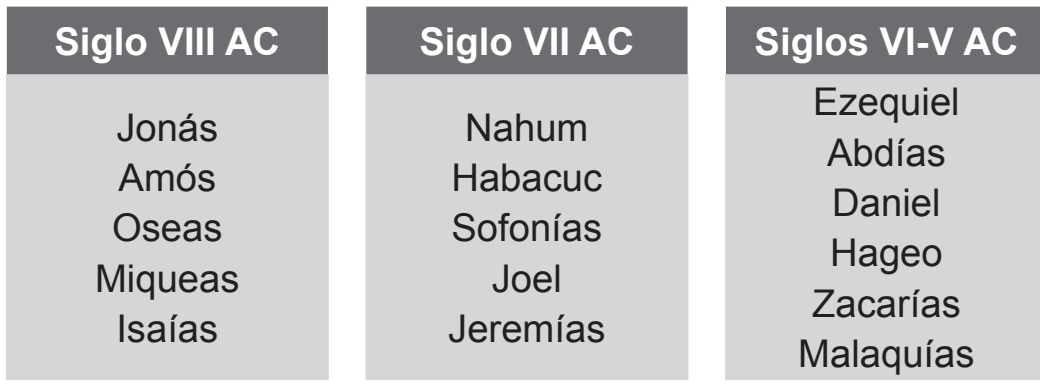

Con la ayuda de esta simple línea de tiempo, esperamos poder demostrar como el pensamiento teológico

${ }^{21}$ Representando esta tendencia está la declaración de Cooper: "Somos dejados . . solo con dos sensibles y productivas maneras de lectura: (1) leyendo estrictamente en un escrito canónico y (2) leyendo desde un punto de vista histórico o un punto de vista crítico-literario". Luego él opta por el último concepto: "Permitan que el texto asuma una existencia indefinida de algún punto indefinido entre el autor y el lector . . . El texto cortado de sus ámbitos históricos, cooperará con nosotros y nos enriquecerá si se lo permitimos". Alan M. Cooper, "The Life and Times of King David according to the Book of Psalms" en Richard E. Friedman, ed., The Poet and the Historian: Essays in Literary and Historical Biblical Criticism (Chico: Scholars Press, 1983) 130-131.

${ }^{22}$ Sin entrar en discusiones detalladas de fechación de los profetas bíblicos individualmente los agruparemos ampliamente por siglos. Si aparecieran algunos detalles adicionales necesarios sobre la fechación ellos aparecerán más adelante bajo las secciones relevantes. 
durante el período reflejado en la literatura profética del Antiguo Testamento ha sido formado progresivamente por un retorno hermenéutico continuo a este punto central de los orígenes, el cual es la creación.

Esto también implica que yo considero a la literatura profética del Antiguo Testamento como subsecuente al Urgeschichte (Gén 1-11), un punto que puede ser argüido tanto sobre un nivel histórico como literario, ${ }^{23}$ pero que eventualmente se tornará más aparente cuando pueda ser demostrado cómo los profetas estuvieron constantemente mirando "retrospectivamente" hacia la creación. De esta manera, Génesis 1-3 se torna el punto de referencia hacia el cual los profetas se tornan cuando emplean los términos y motivos de la creación. ${ }^{24}$

${ }^{23} \mathrm{La}$ emergencia del criticismo literario atestigua la frustración creciente con los esquemas de datación crítico-histórico tradicional, especialmente en lo que respecta al Pentateuco. "El cambio [de lo histórico hacia lo literario o criticismo literario] derivado en parte de una insatisfacción con los así llamados resultados asegurados del criticismo bíblico. Por un lado hubo un sentido creciente de que los logros del criticismo histórico estaban sencillamente asegurados". L. Daniel Hawk, "Literary/Narrative Criticism", en T. Desmond Alexander y David B. Baker, eds., Dictionary of the Old Testament: Pentateuch (Downers Grove: InterVarsitity Press, 2003) 537. Esto de ningún modo significa que haya sido la aseveración solo de los eruditos evangélicos, sino que incluye toda clase de categorías de orientación académica. Ver Hans-Christoff Schmitt, “Die Hintergründe der neuesten Pentateuchkritik und der literasche Befund der Josefsgeschichste Gen 37-50", Zeitschrift für die Alttentestamentliche Wissenchaft 97:2 (1985) 161. Sailhamer ha sido prominente demostrando la progresión narrativa y la unidad del Pentateuco que a su vez provee el punto de referencia canónico para los profetas. John H. Sailhamer, The Pentateuch as Narrative: A biblical and Theological Commentary (Grand Rapids: Zondervan, 1992); Idem, "The Canonical Approach to the Old Testament: Its Effect to Understand Prophecy", JETS 30:3 (1987) 307-315.

${ }^{24}$ Para una discusión sobre la diferencia entre la terminología y el motivo de la creación ver Paas, Creation and Judgement, 58-60. 


\subsection{Indicadores de la creación}

A fin de reconocer los indicadores textuales de la creación, nuestro criterio tiene que ser lo suficientemente amplio a fin de moverse más allá de un nivel puramente semántico, pero también lo suficientemente reducido para conectarnos positivamente con el relato de la creación del Génesis. Un rango amplio de dispositivos que a menudo pertenecen a discursos totalmente diferentes, son invocados por los eruditos a fin de identificar la creación en los profetas: alusión, tradición, motivo, tema, imaginería, metáfora, etc. ${ }^{25}$ Es probablemente seguro dividir estos dentro de tres grupos, (1) lexicológico; (2) literario, y (3) conceptual. En lo que sigue presentaremos ejemplos tomados de la literatura profética del Antiguo Testamento de cada grupo que se reconecta de algún modo con Gén 1-3.

\subsubsection{Indicadores léxicos de la creación}

Campo semántico: Los indicadores léxicos en los profetas que salen del campo semántico se centran alrededor del teológicamente más específico ברא "crear" (ejm. Isa 40:26; Amós 4:13) dar forma" (Isa 41:18); el más bien genérico עשטה", "hacer, obrar", y sus derivados (ejem. Isa 45:18; Jer 10:12; Juan

${ }^{25}$ Para una discusión sobre la diferencia entre la terminología de la creación y el motivo, ver Paas, Creation and Judgement, 58-60.

${ }^{26}$ En el Qal y el Nifal el sujeto de ברא siempre es Yhwh, y por tanto esto sirve de terminus technicus para la creación divina, aunque es usado intercambiablemente con las raíces mencionadas abajo. Cf., Raymond C. van Leuwen, "ברא", NIDOTTE 1:731-732. 
1:9) y el más solemne "פע", "hacer, producir" (ejm. Isa $45: 9,11)$, para mencionar solamente los más prominentes que también aparecen en los profetas. ${ }^{27}$ Sin embargo todos estos también describen actividades más allá de la creación como se halla en Gén 1-3 que es un indicador de cómo la reflexión sobre la creación sirvió como un punto de partida para la creación de nuevos significados. ${ }^{28} \mathrm{~S}$

Palabras-pares: En esta conexión se debería mencionar palabras pares como el merismo ארץ שמים, "cielos/tierra" (Isa 37:16) אור/חשך, o "luz/tinieblas" (Isa 42:16; 45:7) que proporciona indicadores fuertes para la creación. ${ }^{29}$

Citas: Por lo general un autor interrumpe el flujo de su argumento con una cita a fin de autenticar, substanciar o expandir su argumento. Aparte de las citas directas que son generalmente introducidas por una fórmula estática (por ejemplo Daniel 9:13), también encontramos notas invertidas del relato de la creación como la de Eze 36:11 donde el orden de los verbos del original Gén 1:28 está al revés, con el propósito de llamar la atención a la conexión entre la teología de la creación y la recreación, i.e., la restauración después del exilio. ${ }^{30}$

${ }^{27}$ Para un tratamiento más exhaustivo cf., Ibíd., 729-731.

${ }^{28}$ Ver por ejemplo Isa 4:5: "Y creará Yhwh sobre toda la morada del monte de Sión, y sobre los lugares de sus convocaciones, noche y oscuridad de día, y de noche resplandor de fuego que eche llamas; porque sobre toda gloria habrá un dosel".

${ }^{29}$ Según Houtman la palabra-par 'cielos y tierra' en el Antiguo Testamento generalmente señala los atributos de Yhwh como Creador (pasado) y Señor de la creación (presente). Ver Cornelius Houtman, Der Himmel im Alten Testament: Israel Weltbind un Weltanschauung Oudtestamentische Studiënn 30 (Leiden-New York-Köln: Brill, 1993) 9

${ }^{30} \mathrm{Cf}$., Paterson, “Creation in Ezekiel”, 494. 
Alusiones: Las alusiones crean marcadores de referencia menos intensas, pero son utilizadas ampliamente en la literatura profética del Antiguo Testamento. Una alusión es una referencia incompleta o fragmentada de otro texto y por lo tanto es menos reconocida fácilmente y es más susceptible a una mala interpretación. ${ }^{31}$ Sin embargo, cuando el profeta dice en Sofonías 1:3 "Destruiré los hombres y las bestias; destruiré las aves del cielo y los peces del mar", la alusión a la creación es hecha mediante la inversión del orden de las criaturas tal como son mencionadas en Gén 1 haciendo una declaración teológica significativa de creación inversa y separación del Creador. ${ }^{32}$

\subsubsection{Indicadores literarios de la creación}

Metáforas: Numerosas metáforas sobre Dios son empleadas por los profetas y algunas de ellas pueden ser usadas como indicadores de la creación. ${ }^{33}$ El uso del participio Qal de יצר refiriéndose a Yhwh como un alfarero en Isa 45:9 sirve como un buen ejemplo para la connotación de creación de esta metáfora. ${ }^{34}$

${ }^{31}$ Craig C. Broyles, "Tradition, Intertextuality and Canon”, en Craig C. Broyles, ed., Interpreting the Old Testament: A Guide for Exegesis (Grand Rapids: Baker Academy, 2001), 167.

${ }^{32}$ De Roche, “Zephaniah I 2-3”, 106.

${ }^{33}$ Para una discusión sobre el uso de metáforas para lo divino cf., Martin Klingbeil, "Metaphors that Travel (and) almost Vanish: Mapping Diachronic Change in the Intertextual Usage of the Heavenly Warrior Metaphor in Psalm 18 and 144". Monografía presentada en el Congreso Anual de la European Association of Biblical Studies, Dresden, 2005 (inédito).

${ }^{34}$ Ver también Isa 29:16; 41:25; 68:4; Jer 18:4, 6; 19:1 y Zac 11:13. 
Poesías: He mostrado en varias partes que los autores de la Biblia hebrea usaron poesía a fin de comunicar contenidos teológicos importantes. ${ }^{35}$ Resulta interesante que la mayoría de los contextos en los cuales se hallan los textos sobre la creación se encuentran en los profetas y son de naturaleza poética. En tanto que en sí mismo tal vez no sería un marcador lo suficientemente fuerte, el uso de la poesía indica la presencia de un tema teológico importante. ${ }^{36}$

\subsubsection{Indicadores conceptuales sobre creación}

Motivos: Aunque Yhwh como un rey es otra metáfora que podría ser mencionada en términos de creación, ${ }^{37}$ en un sentido más amplio, la realeza puede servir como

${ }^{35}$ Martin G. Klingbeil, “Poemas en medio de la prosa: poesía insertada en el Pentateuco", en Gerald Klingbeil, ed., Pentateuco: inicios, paradigmas y fundamentos: estudios exegéticos y teológicos en el Pentateuco - River Plate Adventist University Monograf Series in Biblical and Theological Studies 1 (Villa Libertador San Martín: Editorial Universidad Adventista del Plata, 2004) 61-85.

${ }^{36}$ Para un estudio de la poesía en la literatura profética, ver por ejemplo: David N. Freedman, "Another Look at Biblical Hebrew Poetry", en Elaine R. Follis, ed., Directions in Biblical Hebrew Poetry - JSOTSup 40 (Sheffield: JSOT Press, 1987) 15-16; Lawrence Boadt, "Reflections on the Study of the Hebrew Poetry Today", en Concordia Journal 24 (1998) 163; Stephen A. Geller, "Were the Prophets Poets?", en Robert P. Gordon, ed., "The Place Is too Small for Us": The Israelite Prophets in Recent Scholarship Sources for Biblical and Theology Study 5 (Winona Lake: Eisenbrauns, 1995), 154-165.

${ }^{37} \mathrm{El}$ rey como un constructor y mantenedor del orden del mundo es alusivo a la creación. Cf. Paas, Creation and Judgement, 69-72. 
un motivo que alude a la creación. La realeza en Israel tiene que ver con la creación y mantenimiento del orden mundial creado divinamente. En tanto que Yhwh es el constructor de Jerusalén después del exilio (Jer 24:6), él también es el constructor de Eva en Gén 2:22, mientras en ambas instancias el indicador de creación lexicológico usado es בנה, "construir". 38

Tipologías: Las tipologías preservan la historicidad de los eventos o personalidades del pasado y teológicamente trascienden dentro de la presencia. ${ }^{39}$ La creación como un evento histórico es usado en la literatura profética como un tipo para la restauración presente y futura y los capítulos finales de Isaías usan la referencia a la creación como un tipo para la recreación de un nuevo cielo y tierra (Isa 65:17).

Es evidente que existe un amplio rango de indicadores de la creación que los profetas emplearon en sus escritos para referirse al Urgeshchichte. Algunos de ellos pueden discernirse con facilidad en tanto que otros solo lo son utilizando vínculos sueltos, creando así una cierta medida corrediza sobre la cual las relaciones intertextuales puedan ser construidas. El punto que necesita ser establecido en este estado es la frecuencia con la cual este

${ }^{38} \mathrm{La}$ realeza es también relacionada a juicio y funciona como un motivo de creación en Israel. Cuando Yhwh invita por medio de los profetas a juicio ellos lo hacen en el contexto de un lenguaje cosmológico de creación (ver por ejemplo, Isa 1:2; Jer 2:12). Cf., ibíd., 87-88.

${ }^{39}$ Una definición de tipología la expresa como el "estudio de personas, eventos o instituciones en la historia de la salvación que Dios designó específicamente para prefigurar predictivamente su complimiento escatológicamente antitípico en Cristo y las realidades traídas acerca de Cristo". Richard M. Davidson, "Biblical Interpretation”, en Raoul Dederen, ed., Handbook of Seventh-day Adventist Theological - Commentary References 12 (Hagerstown: Review and Herald Publishing Association, 2000) 83. 
procedimiento hermenéutico fue invocado, indicando que los profetas construían su teología alrededor de temas fundamentales tales como el motivo de la creación.

\section{La creación en los profetas}

A continuación estableceremos marcas fijas en la literatura profética del Antiguo Testamento contra los indicadores mencionados anteriormente. Tal como lo mencionamos arriba seguiremos una secuencia cronológica aproximada, basándonos en nuestras consideraciones intertextuales, ya que el establecimiento de una línea de tiempo es fundamental al evaluar el uso teológico y el desarrollo de la creación en la literatura profética del Antiguo Testamento. Obviamente, un intento de presentar una exhaustiva lista de la creación en dieciséis libros de tamaño diferente cuya suma es casi un tercio del Antiguo Testamento está destinado al fracaso desde el comienzo. Por lo tanto, la única aproximación posible será un recuento panorámico a vuelo de pájaro sobre los libros proféticos donde trataremos de diferenciar desde arriba los modelos de la creación intertextual.

\section{1. Profetas del siglo VIII AC}

Bajo el siglo VIII, nosotros agrupamos a Jonás, Amós, Oseas, Miqueas e Isaías. Jonás, desde luego, dirigió sus profecías hacia la arena internacional, ${ }^{40}$ en tanto que Amós y Oseas las dirigieron al reino del Norte, y

${ }^{40}$ La cual es una sobresimplificación, puesto que el libro de Jonás es algo altamente cargado contra un nacionalismo israelita exclusivista que era prominente durante el reinado de Jeroboam II. (Cf., 2 Rey 14:25). 
Miqueas e Isaías profetizaron en Judá antes o después de la caída de Samaria. ${ }^{41}$ La amplitud geográfica debería darnos una buena indicación de la fuerza penetrante del pensamiento sobre la creación durante este siglo.

\subsubsection{Jonás}

El mensaje de Jonás es pleno de contenido ecológi$\mathrm{CO}^{42}$ y como tal alusivo a la creación. Al presentarse a sí mismo a los marineros, Jonás se define como un seguidor del Dios Creador en un lenguaje que es reminiscente de la creación y del Decálogo: "Yhwh, Dios del cielo, yo adoro/temo a quien hizo el mar y la tierra seca"43 (Jon 1:9). Uno no puede sino notarlo de algún modo problemático aunque muy enfática la construcción oracional donde el predicado (אני ירא) está inserto entre el objeto (ואת־־הוה) y su cláusula calificadora (אשר־עשה). Jonás se ve a sí mismo rodeado por el Dios de la creación, aunque irónicamente él no está muy seguro de adorarlo o temerlo. ${ }^{44}$

${ }^{41} \mathrm{El}$ caso aquí es hecho en base a la unidad de Isaías, un punto que puede ser argumentado ampliamente, especialmente sobre argumentos literarios, recurriendo al vocabulario corriente, temas y teología. Ver por ejemplo, J. Alec Motyer, The Prophecy of Isaiah (Leiceister: InterVarsity Press, 1993). Cf. también Gregory J. Polan, "Still More Signs of Unity in the Book of Isaiah: The Sinificance of Third Isaiah", Seminar Papers, 1997 - Society of Biblical Literature Seminar Papers 36 (Atlanta: Scholars Press, 1999) 224-233.

42“Enfocado sobre los seres humanos y el ambiente, la ecología constituye un tema teológico prominente en todo Jonás". Phyllis Trible, "The Book of Jonah", NIV 482.

${ }^{43}$ Traducción mía.

${ }^{44}$ Considere el doble significado de ירא, "temer, reverenciar", ibíd., 498. 
El descenso progresivo a las profundidades del océano en el salmo de Jonás (Jon 2:2-9 [TM 2:3-10]) indicada por la raíz plena "descender" (Jon 2:6; [TM 2:7]; cf. también 1:3,5) puede ser relacionado con Gén 1-3. Según el Antiguo Cercano Oriente (ACO) y también de algún modo a las cosmologías del Antiguo Testamento, hay una dimensión espacial de arriba y de abajo; i.e., la tierra está descansando sobre pilares en las aguas donde debía de encontrarse el ámbito del Seol..$^{45}$ Todos estos elementos aparecen en el poema de Jonás: él se encuentra a sí mismo arrojado en "el corazón del mar" (Jon 2:4 [TM 2:5])/ / Gén 1:10 y arrojado fuera de la presencia de Dios (Jon 2:5 [TM 2:6]) tal como Adán y Eva fueron echados

${ }^{45}$ En tanto que es importante hacer una diferencia entre las cosmologías del Antiguo Testamento y del ACO, uno necesita recordar que los escritores de las Escrituras hebreas vivían dentro e interactuando con la más abarcante cosmología del ACO a veces incluso polemizándola, criticándola y demitologizándola. Cf. Gerhard F. Hasel, "The Polemic Nature of the Genesis Cosmology", Evangelical Quarterly 46:2 (1974) 81-102. Sin embargo esos textos no fueron escritos con el propósito de bosquejar la cosmología israelita de una manera científica. Los intentos de describir la cosmología israelita basada en el Antiguo Testamento y en la literatura e iconografía del ACO se puede encontrar en los siguientes: Bernd Janowski, "Das Biblische Weltbild: eine metodologische Skizze", en Beate Ego Bernard Janowski, eds., Das biblische Beltbild und seine altorientalischen Kontexte Foschungen zum Altestament 32 (Tübingen: J. C. B. Mohr [Paul Siebeck], 2001) 3-26; Annete Krüger, "Himmel-Erde-Unterwelt: Kosmologische Entwürde in der poetischen Literatur Israels", en Beate Ego Bernard Janowski, eds., Das biblische Beltbild und seine altorientalischen Kontexte Foschungen zum Altestament 32 (Tübingen: J. C. B. Mohr [Paul Siebeck], 2001) 65-83. Ver también Isaak Cornelius, "The Vision Representations of the World in the Ancient Near East and the Hebrew Bible", Journal of the Northwest Semitic Languages 20 (1994) 193-218. Para un resumen breve sobre la diferencia entre la cosmología del ACO y el AT desde una perspectiva evangélica, ver Ernest C. Lucas, "Cosmology", en T. Desmond Alexander and David W. Baker, eds., Dictionary of the Old Testament: Pentateuch (Downers Grove: InterVarsity, 2003) 130-139. 
fuera del Edén (Gén 3:24); el pasa a través de las aguas caóticas (Jon 2:5 [TM 2:6] / / Gén 1:2) y finalmente desciende al Sheol (Jon 2:2 [TM 2:3]) o al abismo (Jon 2:6 [TM $2: 7]) .{ }^{46}$ Jonás se está hundiendo hacia las tinieblas de la muerte, lejos de la luz y la creación, un proceso que es equivalente a la de-creación. ${ }^{47}$

En todo el libro la creación es puesta en yuxtaposición a la humanidad desobediente, en tanto que el Creador es descrito como estando constantemente involucrado en su creación arrojando una tormenta sobre Jonás (Jon 1:4), poniendo un pez para un doble rescate permitiendo que sea engullido el profeta desobediente (Jon 1:17 [TM 2:1]) así como vomitándolo sobre tierra seca (Jon 2:10 [TM 2:11]). Él después prepara una planta (Jon 4:6), una oruga (Jon 4:7), y un viento oriental (Juan 4:8) a fin de hacer volver a su siervo abatido a su cordura. La creación no es solamente un evento del pasado sino que vuelve a ocurrir a través del continuo involucramiento de Yhwh en su creación y con sus criaturas. Pero más aún, toda la creación está engranada hacia los actos de salvación de

${ }^{46} \mathrm{El}$ entendimiento del nombre propio Sheol como una designación poética del sepulcro sin referencia a ninguna forma de existencia continua ha sido demostrada por disertación de Galeniecks: Cf. Erik Galeniecks, "The Nature, Function and Purpose of the term in the Torah, Prophets and Writings", Tesis doctoral en la Universidad Andrews, 2005.

${ }^{47}$ Resulta interesante notar la aparición del santuario de Dios en este contexto. El simbolismo cósmico conectado con el santuario es evidente a lo largo de todo el Antiguo Testamento, en tanto que el templo sobre la tierra sirve como reflexión de su contraparte celestial. De esta manera el santuario sirve como un motivo-creación, como lo ha demostrado Paas, Creation $\mathcal{E}$ Judgement, 88-94. También Bernd Janowski, "Das Biblische Weltbild: eine metodologische Skizze, en Beate Ego Bernard Janowski, eds., Das biblische Beltbild und seine altorientalischen Kontexte - Foschungen zum Altestament 32 (Tübingen: J. C. B. Mohr [Paul Siebeck], 2001) 229-260. 
Yhwh para con la humanidad y el asunto que concluye el libro de Jonás encuentra su respuesta en la presencia del libro en el canon, reiterando la creencia de Jonás en el supremo Dios-Creador tal como declaró irónicamente al comienzo en su confesión a los marineros paganos (Jon 1:9).

\subsubsection{Amós}

La creación en Amós es una analogía de la historia, presentando a Yhwh como el Creador que interactúa continuamente con su creación, y más específicamente con este libro profético, en un contexto de juicio amenazante pero también de salvación. La terminología de la creación aparece predominantemente en los tres himnos (Amós $4: 13 ; 5: 8-9 ; 9: 5-6)$ que tiene una influencia estructural en todo el desarrollo del libro. ${ }^{48}$

Amós 4:13
“.. el que forma
los montes, y crea
el viento, y anuncia
al hombre su
pensamiento; el que
hace de las tinieblas
mañana, y pasa
sobre las alturas
de la tierra; Jehová
Dios de los ejércitos
es su nombre”.

\begin{tabular}{l}
\multicolumn{1}{c}{ Amós 5:8-9 } \\
“.. al que hace \\
las Pléyades y el \\
Orión, y vuelve \\
las tinieblas en \\
mañana, y hace \\
oscurecer el día \\
como noche; el \\
que llama a las \\
aguas del mar, \\
y las derrama \\
sobre la faz de la \\
tierra; Jehová es \\
su nombre; que \\
da esfuerzo al \\
despojador sobre el \\
fuerte, y hace que \\
el despojador venga \\
sobre la fortaleza”.
\end{tabular}

Amós 9:5-6
“El Señor, Jehová
de los ejércitos, es
el que toca la tierra,
y se derretirá, y
llorarán todos los
que en ella moran; y
crecerá toda como
un río, y mermará
luego como el río de
Egipto. Él edificó en
el cielo sus cámaras,
y ha establecido su
expansión sobre la
tierra; él llama las
aguas del mar, y
sobre la faz de la tierra
las derrama; Jehová
es su nombre”.

${ }^{48} \mathrm{Cf}$. Paas, Creation \& Judgement, 324-326. Él además menciona Amós 6:14; 7:1, 4 y 9:11 como textos que aluden a la creación. 
El lenguaje de, la creación es predominante en estos cinco versículos y un número de indicadores sobre la creación lexicales, aparecen en los tres pasajes: ברא, "crear" y יצר, "formar" (Amós 4:13), "hacer" (Amós $4: 13 ; 5: 8)$. Resulta interesante, que todos estos indicadores son participios, una particularidad sintáctica que puede ser encontrada a lo largo de todo el libro de Amós. ${ }^{49}$ No obstante, la actividad creadora de Dios en cada instancia es traída dentro de una relación con la esfera humana indicando cómo la creación influye sobre la vida humana. Uno puede percibir cierta progresión entre los tres himnos en términos de cómo la intervención de Dios impacta sobre la humanidad. En Amós 4:13 Dios revela su intención de juicio a la humanidad, en tanto que Amós 5:8-9 describe el aspecto destructivo del juicio de Dios. Amós 9:5-6 finalmente describe la reacción humana al juicio divino. El aspecto impactante de la presentación de la creación de Amós es que ésta está ligada intrínsecamente al juicio en una forma tal que la creación forma la explicación para la destrucción. Lo que empieza como un himno de alabanza a Yhwh el Creador se torna en una amenazante descripción de Yhwh como el Juez. Esta aparente contradicción ha confundido a muchos eruditos y más probablemente, y

${ }^{49}$ En total se pueden encontrar 47 participios en el libro de Amós. Esto presenta un argumento más contra la sugerencia hecha por algunos eruditos que los himnos han sido añadidos subsecuentemente por otro autor. Pfeifer explica el uso sintáctico de estas formas en Amós como sigue: “Nach Aussagen über das Verhalten einen Personengruppe folgt eine mit dem Participium pluralis + Artikel beginnende Aüsage daruber, wer die Betreffenden sind", Pfeifer, Yahwe als Schöpfer der Welt", 477. Paas también llega a la conclusión "que los himnos son lo suficientemente intercalados con su contexto directo, que nosotros podemos conocer con seguridad que desde su origen ellos pertenecieron con los pasajes a los cuales están ahora conectados", Paas, Creation \& Judgement, 324. 
más deliberadamente también a la audiencia de Amós. La posición de seguridad inherente basada en la creencia de un Dios Creador es desafiada por Amós y ha provisto la base para una falsa autosuficiencia religiosa tornándose ahora en el racional para el juicio, ${ }^{50}$ poniendo al revés la función original de los himnos.

Mediante los himnos, Amós hace claro que Yhwh no es un Dios que podría ser simplemente controlado. Él desafió ciertas posiciones de derechos presupuestos - mediante los cuales el pueblo presumía el derecho de existencia-desde la perspectiva más amplia de la creación de Dios. ${ }^{51}$

La creación puede ser conectada contextualmente y orientada hacia ambos: comodidad y juicio, en tanto que en Amós esta está mayormente dirigida hacia juicio. Aceptar a Yhwh como Creador también implica la aceptación de su poder para de-crear. A primera vista, la creación usada de este modo, está desasociada de la salvación, pero cuando el juicio es entendido como preliminar y parcial a la salvación, entonces la de-creación se torna en un precursor necesario para la de-creación. Amós describe este punto básico para el uso de fórmula de la expresión שמו יהוה, "Yhwh es su nombre" (Amós 4:13; 5:8; 9:6) indicando que éste es Dios y todavía lo es, él "no solo es el Dios que crea, sino también el que destruye". ${ }^{52}$

El libro de Amós concluye con una gloriosa

${ }^{50}$ Uno puede probar esto confrontando la estructura de los oráculos contra las naciones en Amós 1-2, todos los cuales están localizados geográficamente alrededor de Israel, con una fuerza retórica extraordinaria.

${ }^{51}$ Paas, Creation $\mathcal{E}$ Judgement, 324.

${ }^{52}$ Ibid., 429. 
perspectiva de restauración después del juicio (Amós 9:11-15) introducida por la frase cargada de escatología ,ביום האוה, “en este día”. Los pasajes aluden al tema de la creación empleando terminología (por ejemplo בנה, "construir", Amós 9: 11, 14) y la metáfora de Yhwh como rey. De esta manera dentro del pensamiento teológico de Amós el entendimiento correcto de la creación se torna en un prerequisito para la comprensión de la re-creación. ${ }^{53}$

\subsubsection{Oseas}

La creación en Oseas está vinculada con el tema de la creación de Israel como una nación, nuevamente como con Amós en un contexto de juicio pendiente. La creación no es solamente análoga a la historia, sino la historia misma.

Oseas comienza a desarrollar su teología de la creación con una alusión de la de-creación en Oseas 4:1-3 donde aparece un interesante orden reverso de la creación tal como se presenta en Gén 1. Dios aparece teniendo una "controversia, caso" con o contra Israel (Ose 4:1) el cual en la relación enfocada en el contexto de Oseas podría ser más entendida como una pelea entre marido y mujer que solo constituye la metáfora resaltante del libro. ${ }^{54}$ En base a los pecados de Israel (Oseas 4:2), Oseas 4:3 invoca juicio mediante la introducción de la creación, viz. el tema de la anti-creación: "Por lo cual la tierra se endechará, y

\footnotetext{
${ }^{53}$ Ibid., 195.
}

${ }^{54}$ Deroche asume suficiente evidencia para entender ריב , como una controversia o lucha que podría ser establecida en o fuera de la corte y él argumenta por la segunda opción, ya que en el contexto de Oseas tenemos una situación de solo dos partes involucradas (Dios e Israel) en tanto que en un juicio se necesitaría de un juez. Deroche, "Creation in Hosea", 408-409. 
todo viviente en ella será exterminado, con las bestias del campo y las aves del cielo; y aun los peces del mar serán extinguidos ${ }^{\prime \prime 5}$ (mi propia traducción). Los tres grupos de animales representan las tres esferas donde es hallada la vida sobre la tierra, y lo inverso de su orden como es conocido en la creación ${ }^{56}$ invoca la idea de juicio como de-creación, donde precisamente la creación se consume al ser confrontada y abusada a por el pecado.

La afinidad entre Ose 6:2 y Deu 32:39 difícilmente puede ser pasada por alto en este texto y constituye otro motivo de creación en Oseas, ${ }^{57}$ y la referencia a Yhwh como el que pone la muerte pero también el que resucita, señalando al Dios de la creación que es un tema fuertemente desarrollado en el cántico de Moisés. Oseas 8:14 toma el mismo motivo estableciendo de nuevo una relación con el Pentateuco al usar el epíteto de la creación divina עשה, "Hacedor", que también ocurre repetidamente en el cántico de Moisés (Deu $32: 6,15,18)$. Sin embargo, "la noción de la creación conduce hacia la acusación y sentencia y no hacia la alabanza". ${ }^{58}$

${ }^{55}$ La raíz verbal אסף, en el Nifal puede ser traducida como "quitada, reunida", y en paralelismo con la cola precedente como "extinguido". Según Deroche, "las acciones descritas por 'sp son lo opuesto completa y absolutamente de aquellas descritas por $b r^{\prime}$."Ibíd., 405.

${ }^{56}$ Gén 1:20 - peces; Gén 1:20 - aves; Gén 1:24 - bestias; cf. también Gén 1:28 donde es usado el mismo orden para entregar el dominio sobre la creación a la humanidad.

57“Nos dará vida después de dos días; en el tercer día nos resucitará, y viviremos delante de él” (Ose 6:2). Deu 32:39 "Ved ahora que yo, yo soy, y no hay dioses conmigo; yo hago morir, y yo hago vivir; yo hiero, y yo sano; y no hay quien pueda librar de mi mano". Paas señala la afinidad lingüística de estos dos pasajes, Paas, Creation $\mathcal{E}$ Judgement, 431.

${ }^{58}$ Petersen, "World of Creation", 207. 
Posiblemente el texto más fuerte sobre la creación en Oseas se halle en Ose 11:1 y esto sintetiza los pasajes mencionados arriba dentro de la metáfora de Yhwh como Creador y Procreador de Israel: "Cuando Israel era muchacho, yo lo amé, y de Egipto llamé a mi hijo". Este versículo conecta con Ose 1:10 [MT 2:1] ("ellos serán llamados hijos del Dios viviente") y al éxodo, el cual es descrito en terminología de la creación. De esta manera la creación de Israel como una nación durante los eventos históricos conectados con el éxodo de Egipto se torna parte de la creación de Dios. A quien Dios elige, también crea y con eso se crea un vínculo íntimo y eterno como el existente entre un padre y su hijo. Más allá de reiterar e intensificar la teología de la creación, la metáfora es pedagógica en su retórica: "Mediante este tema de la creación de Israel no es tanta la intención de Oseas de matizar el concepto que tenga la gente de Yhwh, sino, más bien confrontarlos con su propia conducta. Ellos son hijos incrédulos"..$^{9}$

\subsubsection{Miqueas}

Las afinidades y puntos intertextuales entre los mensajes de Miqueas e Isaías son numerosos y han sido señalados repetidamente por varios eruditos. ${ }^{60} \mathrm{El}$ pasaje

${ }^{59}$ Paas, Creation \& Judgement, 431.

${ }^{60}$ Más recientemente, Marvin Sweeney, "Micah's Debate with Isaiah", Journal for the Study of the Old Testament 93 (2001) 111-124; Dominic Rudman, "Zechariah 8:20-22 and Isaiah 2:2-4//Micah 4:23: a Study in intertextuality", Biblische Notizen 107-107 (2001) 50-54; Bernard Gosse, "Michée 4,1-5, Isaïe 2,1-5 et les rédacteurs finaux du livre d'Isaïe", Zeitschrift für die alttestamentliche Wissenschaft 105:1 (1993) 98-102. 
citado más a menudo en este contexto es el paralelo casi idéntico encontrado en Miq 4:1-3, 5/ / Isa 2:2-5. Mientras el pasaje pueda ser tomado como argumento para un mensaje profético común de los dos profetas, para el propósito de este estudio, el foco descansa en la imaginería de la creación, la cual es transmitida en un marco escatológico vía la metáfora del monte de Sión. ${ }^{61}$ De acuerdo a la cosmología del Antiguo Testamento Sión descansa en el centro del mundo creado, y Miqueas señala su establecimiento mediante una terminología de creación (כון, “establecer" - Miq 4:1). La creación en Miqueas está enfocada en la destrucción y la consecuente re-creación en el contexto del "día del Señor", con sus implicaciones escatológicas. ${ }^{62} \mathrm{El}$ profeta construye un puente teológico entre la creación, el comienzo y el fin alrededor de la presencia de Dios, tal como es simbolizada por la metáfora del monte de Sión. ${ }^{63}$

\subsubsection{Isaías}

Tal como se mencionó arriba, Deutero Isaías fue el punto de partida para von Rad y otros al establecer una teología del Antiguo Testamento de la creación, en base a la suposición de que Isaías 40-55 podría ser fechado como posexílico. No obstante, estudios recientes cuyo foco es la unidad literaria de Isaías -aunque pocos eruditos toma-

${ }^{61} \mathrm{Cf}$. bajo 3.1.4, con respecto al uso de la metáfora del monte de Sión.

${ }^{62} \mathrm{~A}$ fin de que esto ocurra así se necesita que haya la destrucción precedente como es expresada en Miq 1:3-4.

${ }^{63}$ Para una discusión sobre el monte de Dios como motivo de creación, cf. Paas, Creation \& Judgement, 94-97. 
rían el argumento a su conclusión lógica, i.e., la unidad de autoría-muestran que la teología de la creación está presente a lo largo de todo el libro. En vista de la riqueza del material sobre la creación en Isaías, yo solo me concentraré en una selección de ciertos textos y motivos que demuestran las líneas principales del pensamiento teológico del profeta sobre la creación. Los ejemplos son tomados deliberadamente de todas las tres divisiones propuestas por la erudición crítica.

Tomando la visión del templo de Isaías como un punto de partida cronológico, Isaías 6:1 describe a Yhwh a lo largo de las líneas de la metáfora del rey celestial que ha sido identificado anteriormente como alusivo a la creación. El cántico de la Viña en el capítulo anterior presenta un aspecto importante de la creación al demostrar la interconexión de la creación de Dios y su intervención en la historia, poniéndolo en el contexto de la elección de Israel. ${ }^{64}$ Isa 5:12 provee un concepto adicional de la teología de la creación de Isaías: el pecado en realidad consiste en no reconocer las obras de la creación de Yhwh.

En Isaías 17:7 el profeta toma el tema desarrollado por Amós consistente en Yhwh como 'Hacedor' de la humanidad. La imagen de Yhwh como el alfarero de Isa 29:16 ya ha sido identificada arriba como relacionada con la terminología de la creación y ocurre en todas las tres divisiones del libro $(41: 25 ; 45: 9 ; 64: 8)$. La creación en Isaías se enfoca primeramente en la soberanía de Dios sobre su creación y en el fracaso de la humanidad para

${ }^{64}$ El verbo clave נטע, "plantar" (Isa 5:2, 7) señala a Yhwh como el plantador de un huerto reminiscente de su actividad en la creación cuando "plantó un jardín al oriente, en Edén" (Gén 2:8). 
reconocer su propia posición dentro de este orden del mundo.

Isaías 40-55 ha sido llamado el centro de la teología de Isaías en tanto que Isa 36-39 cumple un rol de conexión uniendo cuidadosamente los capítulos previos con los posteriores. ${ }^{65}$ Se ha alegado que el llamado Deutero-Isaías introduce la creación como un nuevo tópico del libro pero las observaciones precedentes muestran que el tema "es profundamente continuo con la tradición isaiana" ${ }^{66}$ En tanto que la terminología de la tradición abunda en todo el libro, ${ }^{67}$ la creación ocurre en el 40-55 en conexión con el éxodo y la conquista (Isa 41:17-20; 42:13-17; 43:17-21; 49:8-12), poniendo a la creación en la historia. Es más, la creación es puesta junto con la redención (Isa 44:24) señalando hacia la significancia teológica de motivo al introducir a Ciro como el agente de la redención de Dios. De esta manera, el éxodo sirve como una garantía tipológica para la futura redención del exilio babilónico mediante Ciro (Isa 44:28). La manifestación teocéntrica que Dios forma luz y crea oscuridad tanto como paz y maldad (Isa 45:7) sirve como una introducción a Dios, como una metáfora del alfarero (Isa 45:9-13) que ilustra la absoluta soberanía de Dios dentro de los ámbitos de la historia humana. ${ }^{68}$

${ }^{65}$ Cf. Clifford, “Unity of Isaiah”, 2.

${ }^{66}$ Ibid., 16.

67Por ejemplo ברא, "crear": Isa 4:5; 40:26, 28; 41:20; 42:5; 43:1, 7, 15; 45:7-8, 12-18; 48:7; 54:16; 57:19; 65:17-18.

${ }^{68} \mathrm{El}$ cuadro de Dios siendo también responsable por la creación del 
La división final del libro de Isaías (Isa 56-66) se enfoca sobre la creación de Sión con Isa 60-62 al centro de la sección describiendo la ciudad gloriosa. El gran final del libro en Isa 65-66 añade una dimensión escatológica a la teología de la creación en Isaías describiendo la renovación y restauración en términos de creación. Pero la creación es estos capítulos finales no solo se refieren a Sión como un lugar, sino más aún a sus habitantes que necesitan re-creación y transformación: “Mas os gozaréis y os alegraréis para siempre en las cosas que yo he creado; porque he aquí que yo traigo a Jerusalén alegría, y a su pueblo gozo" (Isa 65:18).

Resumiendo la teología isaiana de la creación, lo siguiente se torna aparente. La creación en Isaías 1-39 se enfoca sobre la soberanía de Dios en su creación y el establecimiento de una relación personal con la humanidad, ejemplificada por el uso de la metáfora del alfarero señalando hacia atrás hasta Gén 2. En Isa 40-55 el tema se enfoca en la creación de Israel como una nación en la historia conectando la creación con el éxodo y teológicamente con la salvación. En Isa 56-66 la creación está centrada en la re-creación de Sión y su gente en respuesta al fracaso de un Israel preexílico. Por lo tanto, tenemos

mal encaja bien dentro de la cosmovisión hebrea teocéntrica y lo excluye toda noción de dualismo. Cf. George F. Knight, Servant Theology: A Commentary on the Book of Isaiah 40-55 - International Theological Commentary (Grand Rapids: Eerdmans, 1984) 90. Ver también Deroche quien concluye: "Isa xlv 7, por otro lado, es parte de un oráculo profético, cuyo propósito es reasegurar al lector (¿oyente?) que Yahveh está en el control de los eventos formando la historia del mundo, en este caso en particular los eventos que conllevan al surgimiento de Ciro y la caída del imperio babilónico. El oráculo logra su meta recordando al lector que no hay dios sino Yahweh (vss. 5-6), y que él es el Creador", Michael Daroche, "Isaiah XLV 7 and the Creation of Chaos?", Vetus Testamentum 42:1 (1992) 20. 
un desarrollo secuencial de la teología de la creación que sigue una progresión de crecimiento natural.

\subsection{Profetas del siglo VII AC}

Un nuevo siglo en la literatura profética del Antiguo Testamento es ensombrecida por la grave caída de Samaria (722 AC) y la creciente urgencia para ser oído el mensaje profético de la aproximación del exilio babilónico. Tal como ocurre en el siglo VIII, de nuevo la palabra profética es inaugurada por un mensaje internacional anunciado por Nahum contra los asirios. Habacuc entra en diálogo con su pueblo, en tanto que Sofonías y Joel amplían el significado escatológico del "motivo del día del Señor". Jeremías, el profeta del llanto, finalmente fracasa en advertir con su mensaje el exilio babilónico.

\subsubsection{Nahúm}

La creación en Nahum está conectada al 'día del Señor' y la descripción de sus características es reminiscente a la terminología de la creación: "Él amenaza al mar, y lo hace secar, y agosta todos los ríos; Basán fue destruido, y el Carmelo, y la flor del Líbano fue destruida. Los montes tiemblan delante de él, y los collados se derriten; la tierra se conmueve a su presencia, y el mundo, y todos los que en él habitan" (Nah 1:4-5). Otra vez hay un contexto de de-creación que es guiado por una imaginería cosmográfica. En la teofanía de juicio el orden creado es impactado por su propio creador en una manera que es reminiscente al motivo Chaoskamfp del ACO, en tanto que hay una polémica tocante al reordenamiento del motivo con Yhwh siendo descrito como soberano sobre todos los 
símbolos del poder común en el ACO tales como el mar, las montañas y la tierra. ${ }^{69}$

\subsubsection{Habacuc}

Habacuc ofrece una perspectiva sobre la creación similar a la de Nahum usando imaginería similar en el contexto de de-creación durante la teofanía del 'día del Señor': “Se levantó, y midió la tierra; miró, e hizo temblar las gentes; los montes antiguos fueron desmenuzados, los collados antiguos se humillaron. Sus caminos son eternos" (Hab 3:6). En los siguientes versículos Habacuc describe el impacto de la aparición de Yhwh sobre la creación (Hab 3:7-12). Sin embargo a través del poder destructivo de la de-creación, es realizada la salvación: "Saliste para socorrer a tu pueblo, para socorrer a tu ungido" (Hab 3:13). A lo largo de las mismas líneas la imaginería de la creación también sirve como un punto de referencia para el reconocimiento del Creador: "Porque la tierra será llena del conocimiento de la gloria de Yhwh, como las aguas cubren el mar" (Hab 2:14).

\subsubsection{Sofonías}

Como se ha observado arriba, Sofonías 1:3 introduce una inversión de la creación enumerando los animales en un orden inverso al que fueron ellos originalmente

${ }^{69} \mathrm{Cf}$. Mi estudio sobre Salmo 29 donde trato la naturaleza polémica del motivo del Chaoskamfp en los Salmos. Martin G. Klingbeil, Yahweh Fighting from Heaven. God as a Warrior and God of Heaven in the Hebrew Psalter and Ancient Near Eastern Iconography - Orbicus Biblicus Orientalis 169 (Fribourg and Göttingen: University Press and Vandenhoeck \& Ruprecht, 1999) 84-99. 
mencionados en el relato de la creación en Gén $1 .^{70}$ Más adelante él usa el conocido juego de palabras entre אדם "hombre" y אדמה, "suelo" encontrado en Gén 1. Sin embargo, lo contrario de la creación transmite un fuerte mensaje teológico: “En Gén II, sin embargo, el retruécano (juego de palabras) es usado para indicar la dependencia del hombre sobre aquél de donde él proviene, en tanto que Sofonías lo usa para mostrar la separación del hombre de su Creador, Yhwh. Una situación que involucra un retorno a la edad antes de la creación puede resultar solo en la destrucción del hombre" ${ }^{71}$ Sofonías está describiendo la pérdida de dominio progresiva sobre la creación por la humanidad y su resultante de de-creación. ${ }^{72}$

Aparte de estas alusiones obvias a la creación, Sofonías también se refiere a otro evento de la Urgeschichte, i.e. el diluvio, usando la frase "sobre la faz de la tierra" como una inclusio para el pasaje en Sof 1:1-3 (Cf. Gén 6:7; $7: 4 ; 8: 8)$. Dentro del mensaje de juicio del profeta, el diluvio sirve como un ejemplo de la destrucción presente. ${ }^{73}$

${ }^{70}$ Ver arriba bajo 2.2.1.

${ }^{71}$ Deroche, “Zephaniah I 2-3”, 106.

${ }^{72}$ Deroche añade un pensamiento posterior: "Si Sofonías sabía y usaba tanto los relatos de la creación (i 1-2 $4^{\mathrm{a}}$ y ii $4 \mathrm{~b}$-iii 24), ¿no implica esto que el así llamado relato P de la creación (i 1-2 $4^{\mathrm{a}}$ ) es más anterior de lo que generalmente pensamos y que Gén i-iii (y probablemente todo Gén i-xi) llegaron juntos como una unidad antes del siglo VII AC? Ibíd., 108.

${ }^{73}$ Cf. Petersen, “World of Creation", 209. 


\subsubsection{Joel}

Dentro de la imaginería del 'día del Señor' Joel emplea imaginería de la creación a fin de describir el impacto de la teofanía de Yhwh sobre la creación en ese día del juicio: "El sol y la luna se oscurecerán, y las estrellas retraerán su resplandor. Y Jehová rugirá desde Sión, y dará su voz desde Jerusalén, y temblarán los cielos y la tierra; pero Jehová será la esperanza de su pueblo, y la fortaleza de los hijos de Israel" (Joel 3:15-16 [MT 4:15-16]). El merismo "cielos y tierra" sirve como un indicador de la creación, pero de nuevo, dentro de un contexto negativo de juicio. El evento teofánico es conectado siempre a la experiencia de Dios en la naturaleza y el impacto de su aparición sobre la creación. ${ }^{74}$ Sin embargo, los versículos finales de Joel vuelven al tópico de la re-creación describiendo el futuro de Sión en términos paradisíacos: "Sucederá en aquel tiempo, que los montes destilarán mosto, y los collados fluirán leche, y por todos los arroyos de Judá correrán aguas; y saldrá una fuente de la casa de Jehová, y regará el valle de Sitim" (Joel 3:18 [TM Joel 4:18]). El jardín del Edén es mencionado con anterioridad (Joel 2:3) que habiendo sido destruido por la plaga de langosta está entonces siendo re-creado. De nuevo, una moción linear desde la creación hasta la re-creación puede ser observada con la creación siendo el paradigma en conjunto el paradigma que resalta la historia.

${ }^{74 “} \mathrm{El}$ empleo de material teofánico en los textos proféticos es con el propósito de mostrar, de una manera drástica, la motivación para el mensaje de juicio del profeta". Paas, Creation E Judgemennt, 218. 


\subsubsection{Jeremías}

La creación en Jeremías está tan extensamente presente $^{75}$ que nuevamente nos limitaremos a un número de pasajes clave. El libro comienza con la referencia de la creación del profeta en el vientre de su madre (Jer 1:5) usando el indicador de la creación ציצ, "formar, moldear" que puede ser encontrado en Gén 2:7. La creación de la humanidad como parte de la semana de la creación es repetida en cada nueva creación de una nueva vida humana. ${ }^{76}$

Un repaso de la creación en Jeremías tiene que incluir Jer 4:23-26 el cual conecta con indicadores lingüísticos fuertes al relato de la creación tal como es hallado en Gén 1. El oráculo-de-destrucción posiblemente presenta el relato más fidedigno de de-creación, o lo inverso de la creación, cuando es comparado con Gén 1:2-2: $4^{\text {a }}$. La siguiente tabla adaptada de Fishbane muestra la progresión. ${ }^{77}$

${ }^{75}$ Perdue proporciona un resumen útil de la teología de la creación en Jeremías, sugiriendo la siguientes tres categorías: (1) Dialéctica de la creación y la historia, (2) creación y destino de la humanidad, y (3) sabiduría y creación. Él llega a la conclusión de que tiene que ocurrir un re-hacer de la teología del Antiguo Testamento si la creación recibe su atención adecuada en la teología bíblica. Leo G. Perdue, The Collapse of History: Reconstructing Old Testament Theology - Overtures to Biblical Theology (Minneapolis: Fortress Press, 1994) 141-150.

76“Göttlige Handlungen, die im jahwistischem Schöpfungsbericht den Beggin der Menschheitsges- chichte markieren, wiederholen sich nach holen Zeuchnissen aus dem Jeremiahbuch beim Entstehen eines heden neuen menschilechen Lebens; den Jahwe ist der Gött allen Fleisches' . . vie der Jer 32, 37 formuliert". Ver Helga Weippert, Schöpffer des Himmels und der Erde: Eine Beitrack zur Theologie des Jeremiahbuches - Stuttgarter Bibelstudien 102 (Stuttgarter: Verlag Katholisches, 1981) 13.

${ }^{77}$ Fishbane, “Jeremiah IV 23-26", 152. 


\begin{tabular}{|c|c|c|}
\hline Detalle & Jeremías & Génesis \\
\hline Pre-creación & $\begin{array}{l}\text { sin forma y vacía } \\
\text { (תהו ובהו Jer 4:23) }\end{array}$ & $\begin{array}{l}\text { sin forma y vacía } \\
\text { (תהו ובהו Gén 1:2) }\end{array}$ \\
\hline Primer día & $\begin{array}{l}\text { no había luz } \\
\text { (אור Jer 4:23) }\end{array}$ & $\begin{array}{l}\text { no había luz } \\
\text { (אור Gén 1:3) }\end{array}$ \\
\hline Segundo día & cielos (שמים Jer 4:23) & cielos (שמים Gén 1:8) \\
\hline Tercer día & $\begin{array}{c}\text { tierra: montes } \\
\text { temblando y colinas } \\
\text { oscilando } \\
\text { (ארץ Jer 4:23-24) }\end{array}$ & $\begin{array}{l}\text { tierra: suelo seco } \\
\text { (ארץ Gén 1:9) }\end{array}$ \\
\hline Cuarto día & & $\begin{array}{c}\text { lumbreras } \\
\text { (מארת Gén 1:14) }\end{array}$ \\
\hline Quinto día & $\begin{array}{l}\text { aves habían volado } \\
\text { (עוף Jer 4:25) }\end{array}$ & $\begin{array}{l}\text { que las aves vuelen } \\
\text { (עוף Gén 1:20) }\end{array}$ \\
\hline Sexto día & $\begin{array}{c}\text { no había hombre } \\
\text { (אדם Jer 4:25) }\end{array}$ & $\begin{array}{l}\text { hagamos al hom- } \\
\text { bre (אדם Gén 1:26) }\end{array}$ \\
\hline Séptimo día & $\begin{array}{l}\text { ciudades destruidas } \\
\text { ante su fiera ira } \\
\text { (הרון Jer 4:26) }\end{array}$ & $\begin{array}{c}\text { Sábado } \\
\text { (שבת Gén 2:2-3) }\end{array}$ \\
\hline
\end{tabular}

En tanto que el relato del Génesis termina con un día de descanso, el Sábado, el relato de-creativo de Jeremías termina con un día de furia. La de-construcción de la creación está ocurriendo y uno puede estar seguro de que los oyentes (y los lectores subsecuentes) del mensaje del profeta reconocieron el modelo de la creación. La creación se torna el paradigma para la destrucción y sirve como el punto de partida primeval para la teología contemporánea. "¿Qué actos y palabras podrían estar más investidas con poder que las de la creación?"78

${ }^{78}$ Ibíd., 153. provee una respuesta a la pregunta retórica de Fisbane: 
La antítesis del oráculo-destrucción es provista en Jer 31:35-37 donde dos dichos cortos concluyen el libro de Consolación (Jer 30-31), y con lenguaje de creación apuntan a la imposibilidad de que Jehová destruya a Israel. Sin embargo esto es expresado a lo largo de las líneas de la teología del remanente con referencia a la "simiente de Israel" y su esperanza futura. Jer 4:23-26 y Jer 31:35-37 muestran el rango de posibles aplicaciones de la teología de Isaías dentro de Jeremías, pero más allá de eso muestra que Israel necesita conocer a Yhwh con respecto a su futuro presente: “Así ambos extremos de la expresión testifican el clamor que Israel finalmente debe entrar en términos con Yhwh sobre quien depende únicamente su futuro".$^{79}$

Jeremías 10:12-16 es un himno que celebra el poder creador de Yhwh y está colmado con imaginería sobre la creación:

El que hizo la tierra con su poder, el que puso en orden el mundo con su saber, y extendió los cielos con su sabiduría; a su voz se produce muchedumbre de aguas en el cielo, y hace subir las nubes de lo postrero de la tierra; hace los relámpagos con la lluvia, y saca el viento de sus depósitos. Todo hombre se embrutece, y le falta ciencia; se avergüenza de su ídolo todo fundidor, porque mentirosa es su obra de fundición, y no hay espíritu en ella. Vanidad son, obra vana; al tiempo de su castigo

\footnotetext{
“La teología de la creación funciona aquí para gritar una negación elemental, sin reserva y completa de todo lo que hace vivificar la vida, una negación que difícilmente sería expresada sin un lenguaje tan grande". Brueggemann, "Jeremiah", 156.

${ }^{79}$ Ibid., 159.
} 
perecerán. No es así la porción de Jacob; porque él es el Hacedor de todo, e Israel es la vara de su heredad; Yhwh de los ejércitos es su nombre (Jer 10:12-16).

Aunque la mayoría de los comentadores señalan el contraste entre el verdadero Dios y los ídolos, el énfasis es más bien entre Yhwh como el creador de la vida (Jer 10:13) y la humanidad como (falsa) creadora de vida (Jer 10:14). El foco no está en el ídolo sino en su hacedor quien es avergonzado por su imagen inanimada, puesto que no es capaz de proporcionar a la criatura con el aliento de vida necesario lo que es la característica distintiva de la creación de Yhwh.

La idolatría es un doble pecado. La adoración de los ídolos niega la realidad del completo control de Dios sobre el cosmos porque esto implica el reconocimiento de otros poderes divinos ... Peor aún es la pretensión de crear vida. Al hacer esto, la humanidad reclama el conocimiento divino". 80

\subsection{Profetas de los siglos VI-V AC}

El exilio babilónico y el período posexílico trajeron consigo un cambio en el mensaje profético, cambiando su contenido hacia la restauración o, hablando dentro de la terminología del presente artículo, a la re-creación. En tanto que Ezequiel y Abdías atestiguan la caída de Jerusalén, y como tal el último cumplimiento de la largamente profetizada de-creación, Daniel trae una dimensión apocalíptica al tópico. La re-creación se tor-

\footnotetext{
${ }^{80}$ Rudman, "Creation and Fall”, 68.
} 
na en el tópico prominente para el posexílico Hageo y Zacarías, y Malaquías finaliza el coro profético canónico del Antiguo Testamento con el mensaje de restauración del profeta Elías.

\subsubsection{Ezequiel}

Petersen llega a la conclusión que "las tradiciones de la creación no son importantes para el argumento teológico de Ezequiel" ${ }^{81}$ Sin embargo su argumento parece estar basado en la suposición de una lectura positiva exclusiva del relato de la creación, tal como fue visto, que forma solo una parte del panorama teológico por el cual los motivos de la creación fueron invocados. Entendido de esta manera, Ezequiel "no está preocupado en cómo llegó este mundo a la existencia ...., sino más bien con la reformación de un mundo que ha ido muy lejos en el pecar" ${ }^{82} \mathrm{~A}$ fin de ilustrar esto, enfocaré sobre tres pasajes que bosquejan el uso teológico de la creación de Ezequiel.

Eze 28:11-19 es un oráculo teológico que se centra en una descripción del rey Tiro como un tipo del querubín anárquico que ha sido interpretado desde tiempos patrísticos como señalando la caída de Lucifer. ${ }^{83}$ Un número de indicadores lingüísticos sobre la creación están

${ }^{81}$ Petersen, “Creation in Ezekiel”, 499.

${ }^{82}$ Gallambush, "Castles in the Air", 147.

${ }^{83}$ Ver por ejemplo Jean Marc Vercruysse, “Les Pere de l'église et le chute de l'ange (Lucifer d'apres Is 14 et Ez 28"), Revue de sciences religeusis 75:2 (2001) 147-174. 
presentes, ${ }^{84}$ sin embargo el contexto del pasaje se enfoca sobre la descripción de la codicia de un ángel caído que está contaminando un mundo perfecto. Así con Jeremías, el lenguaje de la creación es empleado como un poderoso paradigma para describir el origen del pecado.

Eze 31:1-18 transfiere el mismo escenario al ámbito de la historia humana. El árbol cósmico representando a la realeza humana es un motivo harto conocido en la iconografía del $\mathrm{ACO},{ }^{85}$ es usado como una metáfora para la caída del rey de Asiria que a su vez sirve como una advertencia al juicio futuro de Egipto. El capítulo describe la gloria del árbol dentro de la terminología de la creación y la cosmología (por ejemplo: תהום Eze 31:4/ / Gén 7:11) y lo conecta con el paraíso (Eze 31:8-9, 18). La terminología de la creación es empleada para describir la caída de dos naciones prominentes, Asiria y Egipto. De esta manera, no solamente el paraíso ha sido estropeado sino también la historia humana.

La re-creación en Ezequiel y el reverso de la decreación, tal como es ejemplificado en los dos pasajes anteriores, puede encontrarse en Eze 47:1-12 dentro del contexto de la visión de la gloria futura del templo, el cual en sí mismo sirve como un motivo de la creación. ${ }^{86}$ Esta vez los árboles están creciendo de nuevo no en rebelión

84Por ejemplo:ברא, "crear" (Gén 1:1/ / Eze 28:13, 15; עדן, "Edén" (Gén 2:8, 10, 15//Eze 28:13; varias gemas preciosas (Gén 2:11-12//Eze 28:13); כרוב, “querubín" (Gén 3:24//Eze 28:14, 16).

${ }^{85}$ Othmar Keel, Goddesses and Trees, New Moon and Yahweh. Ancient Near Eastern Art and the Hebrew Bible - JSOTSup 261 (Sheffield: Sheffield Academic Press, 1988).

${ }^{86}$ Cf. nota 47. 
contraria sino bajo el poder de Yhwh y la provisión de la fertilidad (Eze 47:12). ${ }^{87}$ Los agentes sostenedores del poder de Dios son los ríos del paraíso que Ezequiel conecta a la creación en el relato de Gén 2:10-14. ${ }^{88}$ Ezequiel une deliberadamente templo/Sión con la imaginería del paraíso, porque la destrucción del templo terrenal de Jerusalén y su propio exilio ha causado que el lugar de la presencia de Dios trascienda al ámbito celestial, indicando que la presencia de Yhwh es continua y no depende de realidades humanas.

Tal como revelan las conexiones entre Eze 47:1-2 y Gén 2:10-14, Ezequiel entendió el símbolo de Sión de una nueva manera. Libera a partir de la referencia explícita a las realidades temporales políticas de la monarquía, sacerdocio y templo terrenal, el monte del templo y el río de la última gran visión de Ezequiel para establecerlas como símbolos infinitos de la presencia divina. Para Ezequiel, la Sión terrenal, con su ciudad y templo, era un chasco amargo ${ }^{89}$

La creación en Ezequiel es usada para expresar su chasco sobre la rebelión angélica y la consecuente historia humana que vuelve a ejecutar la rebelión vez tras vez,

${ }^{87 “ E l ~ e ́ n f a s i s ~ d e ~ E z e q u i e l ~ s o b r e ~ l o s ~ a ́ r b o l e s ~ c o m o ~ s i g n o s ~ i n d i c a n d o ~}$ aceptación o rebelión contra la autoridad divina aparece en contraste admirable con el simbolismo de los árboles en diferentes partes de la Biblia hebrea". Gallambush, "Castles in the Air", 155.

${ }^{88}$ Hay indicadores de la creación significantes en el texto; por ejemplo נפט היח, "ser viviente" (Eze 47:9//Gén 1:21, 21, 24, 30); שרץ, "pulular" (Eze 47:9//Gén 1:20-21).

${ }^{89}$ Steven Tuell, “The Rivers of Paradise”, 189. 
pero él se mueve más allá de eso declarando que Dios es capaz de recrear algo de los jirones de la historia humana. Sin embargo, hay que tener cuidado de no atribuir una exclusiva de lo mundano a las profecías de Ezequiel. ${ }^{90}$

\subsubsection{Abdías}

No hay una terminología de la creación aparente empleada en el libro de Abdías excepto por el uso del motivo del templo de Sión (Abd 1:17,21) que está en yuxtaposición con las montañas de Edom (Abd 1:3-4, 8-9). El que "ha hecho su nido "entre las estrellas" (Abd 1:4) será traído abajo por causa de su sabiduría y entendimiento humano (Abd 1:8). En cambio, las montañas de Esaú será gobernadas desde el monte de Sión (Abd 1:21). ${ }^{91}$

\subsubsection{Daniel}

Existen pocos estudios que unen el libro de Daniel con la teología de la creación, y aquellos que asumen la tarea generalmente se concentran en el motivo mitológico del Chaoskampf y sus contrapartes del ACO como se encuentra en la descripción de las aguas en Daniel 7:23. ${ }^{92}$ De acuerdo con Wilson, en contraste con Gén 1, "el

${ }^{90}$ Uno no debe olvidar la visión del profeta de los huesos secos en Eze 37 que emplea la terminología de la creación en la re-creación de la casa de Israel.

${ }^{91} \mathrm{Cf}$. bajo 1.3.4. con respecto al uso de la metáfora del monte de Sión.

${ }^{92}$ Ver por ejemplo: Adré Lacocque, "Allusions to Creation in Daniel7", en The Book of Daniel: composition and reception. Volume one, en Jon Joseph Collins and Peter W. Flint, eds., Formation and Interpretation of Old Testament Literature 2:1 - Vetus Testamentum Supplement 83.1 (Leiden; 
mundo estaba revertido a su estado de pre-creación y está claramente en necesidad de re-creación" ${ }^{93}$ Esta recreación es lograda en la visión del "Anciano de días" que constituye la segunda parte de la visión (Dan 7:9-14 con la palabra שלטן, "dominio" siendo la palabra clave que aparece ocho veces en este capítulo. ${ }^{94} \mathrm{El}$ fracaso del dominio humano sobre la tierra en la historia, como es ordenado en la creación, es remplazado por el dominio de Dios mediante un reino eterno.

Además, aparte de Daniel 7, hay más sobre la creación como lo ha mostrado Doukhan. Él sugiere el asunto desde una perspectiva lingüística y llega a concluir que "les allusions a la creation foisonnent tout au long du libre et son attestéets d'une maniere ou d'une autre dans chacun de ses chapitres". ${ }^{95}$ En lo que sigue hemos seleccionado las alusiones más importantes mencionadas por Doukhan.

En Dan 1:12, los jóvenes optan por un menú que está haciendo eco de la dieta previa a la caída encontrada en Gén 1:29 y la prescripción de Nabucodonosor en el 2:38 invoca la terminología de la creación invocando el mismo atributo del dominio sobre la tierra y todas sus criaturas al rey de Babilonia tal como Adán recibió en Gén 1:28. La arcilla que es parte de los pies de la estatua

Boston: Brill, 2001) 114-131.

${ }^{93}$ Wilson, "Creation and New Creation", 201-202.

${ }^{94} \operatorname{Dan} 7: 6,9,14(3 x), 26,27(2 x)$.

${ }^{95}$ Jacques Doukhan, "Allusions to creation dans le livre de Daniel", en Adam S. van der Woude, ed., The Book of Daniel in the Light of New Findings - Bibliotheca Ephemeridum Theoligicarum Lovaniensium (Leuven: University Press and Peeters, 1993), 289. 
es usada a lo largo de la Biblia dentro de los contextos que aluden a la creación indicando el aspecto religioso de la Roma espiritual (Cf. Isa 29:16; Jer 18:2; Lam 4:2). En la palabra-par אור/חשך, "tinieblas/luz" en la bendición de Daniel (Dan 2:22) resuena el relato de la creación de Gén 1:4-5. Otra palabra-par de creación (ארץ/שמים, "cielos/tierra") se encuentra en la oración de Nabucodonosor tras volver a su sano juicio en Dan 4:35. Además el uso del motivo del árbol cósmico en Daniel 4 apunta al relato de la creación (cf. Dan 2:9). La asociación de los dos shegolates בקר ערב, "tarde mañana" en Daniel 8:14 se encuentra en esta secuencia y significado solamente en la historia de la creación (Gén 1:5, 8, 13, 19, 23, 31). En el capítulo final del libro, Daniel evoca la terminología de la creación describiendo la re-creación que ocurrirá después del escenario de de-creación del capítulo anterior (Dan 11). Para los justos hay un cambio desde durmiendo en el polvo (Dan 12:2) a brillando como las estrellas (Dan 12:3) y para Daniel en particular con descansar a levantarse en el día final para recibir su herencia (Dan 12:13). ${ }^{96}$

Los temas apocalípticos de transformación en la historia y retorno final a un estado edénico que son tan recurrentes en el libro de Daniel, son agrupados teológicamente a lo largo de un proceso de creación a de-creación y finalmente re-creación, un tema que encontramos repetidamente en la literatura profética del Antiguo Testamento, mientras que en las líneas de Daniel son más amplias e informadas por su perspectiva apocalíptica. La escatología que se mueve hacia un final, imperativamente necesita de un comienzo, y el tema de la creación pro-

${ }^{96}$ Ibid., 286-289. 
porciona el racional teológico contra el cual la escatología puede acontecer. ${ }^{97}$

\subsubsection{Hageo}

En Hageo 1:10 el profeta invoca el mesmerismo cielos/tierra demostrando como la falta de fidelidad de la comunidad posexílica está causando que las bendiciones de la naturaleza o de la creación sean interrumpidas. Más adelante Hageo emplea el mismo par de palabras para describir cómo el orden creado es afectado por 'el día del Señor' pero esta vez desde una perspectiva mesiánica: "Porque así dice Yhwh de los ejércitos: De aquí a poco yo haré temblar los cielos y la tierra, el mar y la tierra seca; y haré temblar a todas las naciones, y vendrá el Deseado de todas las naciones; y llenaré de gloria esta casa, ha dicho Yhwh de los ejércitos (Hageo 2:6-7; cf. 2:21-22).

\subsubsection{Zacarías}

Dios como el continuo sustentador es descrito en Zacarías: "Pedid a Yhwh lluvia en la estación tardía. Jehová hará relámpagos, y os dará lluvia abundante, y hierba verde en el campo a cada uno" (Zacarías 10:1). El "Pedid a Yhwh lluvia en la estación tardía. Yhwh hará relámpagos, y os dará lluvia abundante, y hierba verde en el campo a

97 “L'idée de commencement es conséquente avec celle de 'fin'. L'ídée de determinismo rejoint celle de résurrection. L'idée de determinismo rejoint celle de contrôle de l'histoire par Dieu. L'idée de universalisme est impliquée dans la conception cosmique du salud. En fin est surtout, l'idée de surtout souveraineté et du royaume de Dieu qui est centrale dans tout le libre de Daniel, releve de la même pensé créateur (Ps 24,1-2, 7-10; cf. 95, 3-6), ibíd., 290-1. 
cada uno". El עששב בשדה, "vegetación en el campo" conecta con שעב בשדדה, "vegetación en el campo" de Gén 2:5. La primavera y la fertilidad son causadas por el proceso continuo de 'crear' "עשטה" la lluvia de las nubes. El segundo oráculo de Zacarías משא, "profecía, oráculo" (cf. 9:1) es introducido mediante el uso de una distinta terminología de la creación, sin embargo con un significativo arreglo nuevo de la terminología de la creación: "Profecía de la palabra de Yhwh acerca de Israel. Yhwh, que extiende los cielos y funda la tierra, y forma el espíritu del hombre dentro de él ..." (Zac 12:1). En tanto que el "extiende los cielos" no es un indicador lingüístico directo de la creación, él sin embargo recaptura la acción de Gén 1:6-7 y es encontrado a lo largo de Antiguo Testamento (Cf. Sal 104:2; Job 9:8; Isa 44:24). Es también interesante notar que el objeto de "יצר", "formar" en Zac 12:1 no es el mismo hombre como en Gén 1:7 sino רוח אדם, "el espíritu del hombre".

Aquí uno tiene la sensación que hay un grupo tradicional de vocabulario de la creación pero que podría estar arreglado en varios modelos aceptados. Cielos, tierra, humanidad y espíritu proporcionan los bloques construidos cruciales. Zacarías 12:1 los combina dentro de una manera innovada y hábil. ${ }^{98}$

De manera interesante, Zac 12:1 sirve dentro del género literario dado como una validación para el siguiente oráculo el cual es una descripción del nuevo y victorioso rol de Israel entre las naciones, una nueva creación de la nación en el día del Señor.

\footnotetext{
${ }^{98}$ Petersen, “World of Creation”, 210.
} 


\subsection{Malaquías}

Malaquías concluye el ciclo de los profetas del Antiguo Testamento con una pregunta retórica que hace un paralelo de Dios como el Creador con la metáfora de Dios como un padre: " ¿No tenemos todos un mismo padre? ¿No nos ha creado un mismo Dios? ¿Por qué, pues, nos portamos deslealmente el uno contra el otro, profanando el pacto de nuestros padres? (Mal 2:10)." La creación aquí está siendo transformada al nivel de intimidad de padre-hijo, vis. esposo-esposa (cf. Mal 2:14-15) lo cual hace eco de la creación íntima relatada en Gén 2. La creación en el libro final del Antiguo Testamento no está centrada en la cosmogonía sino en una relación personal entre Dios y la humanidad tal como es ejemplificada en el orden de la creación.

\section{Resumen y conclusiones}

\section{Profetas del siglo VIII AC}

\begin{tabular}{|c|c|c|c|c|}
\hline Jonás & Amós & Oseas & Miqueas & Isaías \\
\hline $\begin{array}{l}\text { - Conteni- } \\
\text { do ecoló- } \\
\text { gico } \\
\text { - El des- } \\
\text { censo } \\
\text { progre- } \\
\text { sivo de } \\
\text { Jonás } \\
\text { refleja } \\
\text { un mo- } \\
\text { vimiento } \\
\text { fuera de } \\
\text { la crea- } \\
\text { ción, de } \\
\text { la vida } \\
\text { hacia la } \\
\text { muerte. }\end{array}$ & $\begin{array}{l}\text { - La creación } \\
\text { es análoga } \\
\text { a la historia } \\
\text { - La creación } \\
\text { se torna en } \\
\text { un para- } \\
\text { digma para } \\
\text { juicio (de- } \\
\text { creación) y } \\
\text { salvación } \\
\text { (re-creación) }\end{array}$ & $\begin{array}{l}\text { - La crea- } \\
\text { ción es } \\
\text { historia } \\
\text { - La rever- } \\
\text { sión del } \\
\text { orden de } \\
\text { la crea- } \\
\text { ción con } \\
\text { el fin de } \\
\text { describir } \\
\text { anti-crea- } \\
\text { ción }\end{array}$ & $\begin{array}{l}\text { - La crea- } \\
\text { ción se } \\
\text { enfoca en } \\
\text { de- y sub- } \\
\text { secuente } \\
\text { re-creación } \\
\text { escatoló- } \\
\text { gica }\end{array}$ & $\begin{array}{l}\text { - La crea- } \\
\text { ción está } \\
\text { presente } \\
\text { a lo largo } \\
\text { de todo } \\
\text { el libro }\end{array}$ \\
\hline
\end{tabular}




\begin{tabular}{|c|c|c|c|c|}
\hline Jonás & Amós & Oseas & Miqueas & Isaías \\
\hline $\begin{array}{l}\text { - La crea- } \\
\text { ción obe- } \\
\text { diente } \\
\text { contra la } \\
\text { huma- } \\
\text { nidad } \\
\text { desobe- } \\
\text { diente }\end{array}$ & $\begin{array}{l}\text { - Un entendi- } \\
\text { miento co- } \\
\text { rrecto de la } \\
\text { creación es } \\
\text { prerrequisito } \\
\text { para la re- } \\
\text { creación }\end{array}$ & $\begin{array}{l}\text { - La crea- } \\
\text { ción de Is- } \\
\text { rael como } \\
\text { nación } \\
\text { durante } \\
\text { el éxodo } \\
\text { forma } \\
\text { parte de la } \\
\text { creación } \\
\text { original } \\
\text { - La elec- } \\
\text { ción } \\
\text { significa } \\
\text { creación }\end{array}$ & $\begin{array}{l}\text { - Monte de } \\
\text { Sión como } \\
\text { puente } \\
\text { teológico } \\
\text { entre crea- } \\
\text { ción y re- } \\
\text { creación }\end{array}$ & $\begin{array}{l}\text { - Metáfo- } \\
\text { ras de la } \\
\text { creación } \\
\text { como } \\
\text { "arcilla" } \\
\text { "alfarero" } \\
\text { estable- } \\
\text { cen una } \\
\text { relación } \\
\text { personal } \\
\text { - La crea- } \\
\text { ción en } \\
\text { la histo- } \\
\text { ria sirve } \\
\text { como } \\
\text { una ga- } \\
\text { rantía } \\
\text { para la } \\
\text { reden- } \\
\text { ción }\end{array}$ \\
\hline
\end{tabular}

Al tratar de establecer las líneas más amplias de la creación en la literatura profética del siglo VIII AC, se torna aparente que la creación está anclada progresivamente en la historia, es hecha relevante en la salvación, y centrada paradigmáticamente en la introducción de la triada de creación-de-creación-re-creación.

\begin{tabular}{|c|c|c|c|c|}
\hline \multicolumn{5}{|c|}{ Profetas del siglo VII AC } \\
\hline Nahum & Habacuc & Sofonías & Joel & Jeremías \\
\hline $\begin{array}{l}\text { - Termino- } \\
\text { logía de } \\
\text { la crea- } \\
\text { ción usa- } \\
\text { da para } \\
\text { describir } \\
\text { el "día } \\
\text { del Se- } \\
\text { ñor" }\end{array}$ & $\begin{array}{l}\text { Creación } \\
\text { como de- } \\
\text { creación } \\
\text { en el "día } \\
\text { del Señor" }\end{array}$ & $\begin{array}{l}\text { - Reversión } \\
\text { de la } \\
\text { creación } \\
\text { indica la } \\
\text { separa- } \\
\text { ción entre } \\
\text { el Crea- } \\
\text { dor y la } \\
\text { criatura }\end{array}$ & $\begin{array}{l}\text { - De-creación } \\
\text { escatológica } \\
\text { pero reden- } \\
\text { ción para su } \\
\text { pueblo. }\end{array}$ & $\begin{array}{l}\text { - Relato más } \\
\text { fuerte de } \\
\text { creación } \\
\text { inversa en } \\
\text { la literatura } \\
\text { profética } \\
\text { - Creación } \\
\text { se torna en } \\
\text { el paradig- } \\
\text { ma de la } \\
\text { destrucción }\end{array}$ \\
\hline
\end{tabular}




\begin{tabular}{|c|c|c|c|c|}
\hline Nahum & Habacuc & Sofonías & Joel & Jeremías \\
\hline $\begin{array}{l}\text { Sobe- } \\
\text { ranía } \\
\text { de Dios } \\
\text { como } \\
\text { Creador } \\
\text { sobre los } \\
\text { símbolos } \\
\text { de poder } \\
\text { del ACO }\end{array}$ & $\begin{array}{l}\text { De-crea- } \\
\text { ción tiene } \\
\text { por objeto } \\
\text { obtener la } \\
\text { salvación } \\
\text { y recono- } \\
\text { cimiento } \\
\text { del Crea- } \\
\text { dor }\end{array}$ & $\begin{array}{l}\text { - De- } \\
\text { creación } \\
\text { progresiva } \\
\text { resulta en } \\
\text { pérdida de } \\
\text { dominio } \\
\text { sobre la } \\
\text { creación } \\
\text { - Diluvio } \\
\text { como tipo } \\
\text { para la } \\
\text { de-crea- } \\
\text { ción. }\end{array}$ & $\begin{array}{l}\text { - Re-creación } \\
\text { en términos } \\
\text { paradisía- } \\
\text { cos } \\
\text { - Triada crea- } \\
\text { ción-de- } \\
\text { creación- } \\
\text { re-creación }\end{array}$ & $\begin{array}{l}\text { - Teología } \\
\text { del rema- } \\
\text { nente nos } \\
\text { conecta } \\
\text { con la } \\
\text { creación } \\
\text { - Contraste } \\
\text { entre el } \\
\text { verdadero } \\
\text { Creador } \\
\text { (Yhwh) } \\
\text { y el falso } \\
\text { creador (el } \\
\text { idólatra) }\end{array}$ \\
\hline
\end{tabular}

La creación en la literatura del siglo VII AC está contextualizada históricamente por el inminente exilo babilónico en tanto que la triada creación - de-creación re-creación se torna más y más prominente cuando los profetas comienzan a percibir más allá del inevitable juicio hacia la restauración.

\begin{tabular}{|c|c|c|c|c|c|}
\hline \multicolumn{6}{|c|}{ Profetas de los siglos VI-V AC } \\
\hline Ezequiel & Abdías & Daniel & Hageo & Zacarías & Malaquias \\
\hline $\begin{array}{l}\text { - Enfocado } \\
\text { en refor- } \\
\text { mar un } \\
\text { mundo } \\
\text { de-crea- } \\
\text { do } \\
\text { - La de- } \\
\text { creación } \\
\text { es anun- } \\
\text { ciada en } \\
\text { la caída } \\
\text { de Lucifer }\end{array}$ & $\begin{array}{l}\text { - No hay } \\
\text { una } \\
\text { teología } \\
\text { de la } \\
\text { creación } \\
\text { explícita } \\
\text { con ex- } \\
\text { cepción } \\
\text { del mo- } \\
\text { tivo del } \\
\text { monte } \\
\text { de Sión }\end{array}$ & $\begin{array}{l}\text { - Termino- } \\
\text { logía de la } \\
\text { cre- ación } \\
\text { presente } \\
\text { a lo largo } \\
\text { del libro } \\
\text { apoca- líp- } \\
\text { tico como } \\
\text { transfor- } \\
\text { mación de } \\
\text { la historia } \\
\text { en térmi- } \\
\text { nos de } \\
\text { creación }\end{array}$ & $\begin{array}{l}\text { - El motivo } \\
\text { 'día del } \\
\text { Señor' } \\
\text { con pers- } \\
\text { pectiva } \\
\text { mesiánica } \\
\text { junto con } \\
\text { la termi- } \\
\text { nología } \\
\text { de la } \\
\text { creación }\end{array}$ & $\begin{array}{l}\text { - La crea- } \\
\text { ción en } \\
\text { curso } \\
\text { por me- } \\
\text { dio del } \\
\text { susten- } \\
\text { tamiento } \\
\text { de la } \\
\text { vida } \\
\text { mediante } \\
\text { la fertili- } \\
\text { dad y la } \\
\text { lluvia }\end{array}$ & $\begin{array}{l}\text { - La crea- } \\
\text { ción trans- } \\
\text { formada } \\
\text { al nivel } \\
\text { de una } \\
\text { relación- } \\
\text { personal- } \\
\text { íntima } \\
\text { - La crea- } \\
\text { ción no } \\
\text { basada en } \\
\text { cosmogo- } \\
\text { nía sino } \\
\text { sobre una } \\
\text { relación }\end{array}$ \\
\hline
\end{tabular}




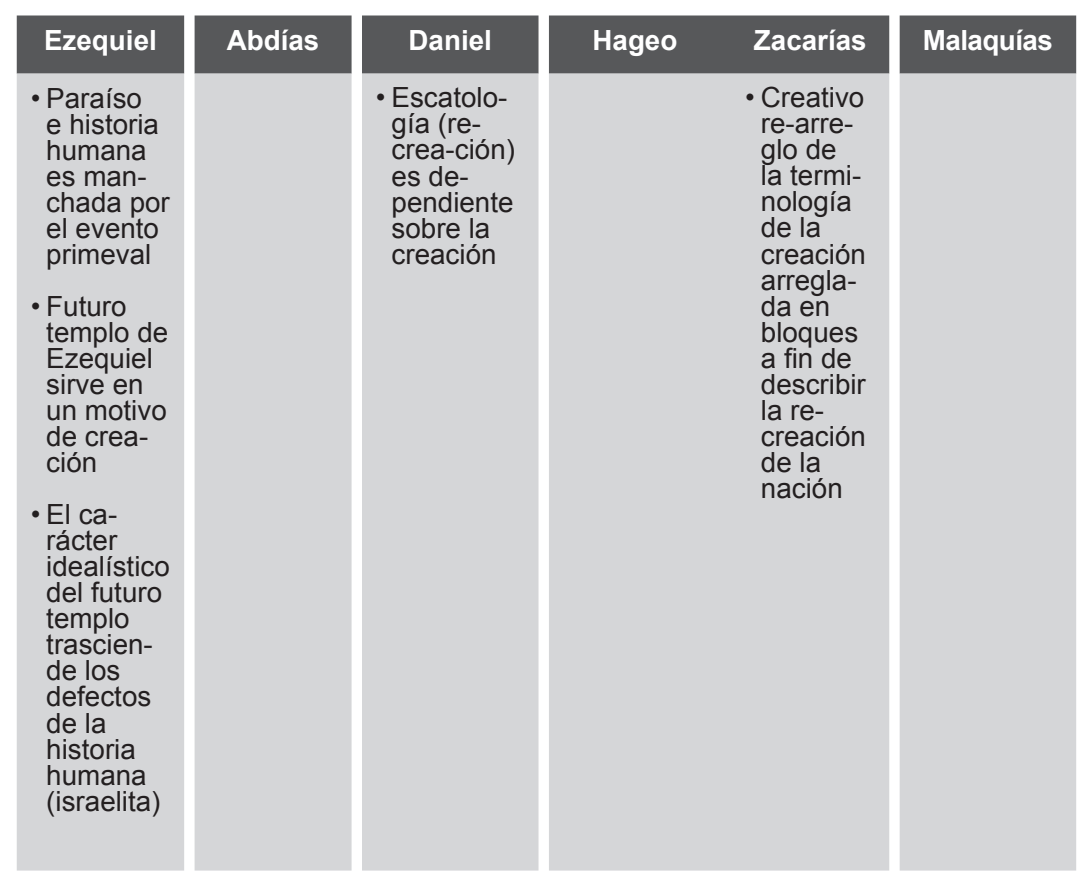

El uso de la creación durante los dos siglos finales de la literatura profética del Antiguo Testamento está orientado claramente hacia el futuro en tanto que ha ocurrido una abstracción teológica que puede ser relacionada con la desaparición física del templo y la monarquía. Sin embargo la creación es todavía el paradigma destacado que abarca la historia humana, el foco se ha trasladado hacia el final del arco, el cual, como en el caso de Daniel, toma nociones apocalípticas así como mesiánicas.

La creación en la literatura profética del Antiguo Testamento es empleada como una constante referencia literaria y teológica que conecta a un pasado histórico, motiva la interpretación del presente, y se mueve hacia una perspectiva del futuro mediante una continua contextualización del tópico, vía la triada de la creación-de-creación-re- 
creación. Este punto de referencia está anclado en el relato de la creación tal como es presentado en Gén 1-3.

Los últimos autores de la Biblia hebrea entendieron la creación no como un tópico entre otros o incluso uno de menor significancia. Para ellos, la creación fue el punto inicial porque todos los seres humanos pueden pensar y decir acerca de Dios y su relación para con el mundo y la humanidad, en base al hecho que él creó todo esto. ${ }^{99}$

Los indicadores intertextuales que señalan a la creación en los profetas indican que ellos vieron la creación como algo literal e histórico dado que la referencia al relato de la creación es hecha indiscriminadamente tal como se presenta en Gén 1-2. El movimiento de intertextualidad indica claramente que tal como la creación forma el punto inicial de mucho del discurso teológico profético, todos los indicadores de la creación, tal como están presentados en este artículo, señalan retrocediendo hasta el modelo de la creación tal como es presentado en Gén 1:3. Aun cuando no ha sido el propósito de este estudio reconstruir la cosmología de los profetas del Antiguo Testamento, se ha tornado evidente que su cosmovisión partía de la creación y explicaba e interpretaba al mundo desde esta perspectiva. Cualquier discusión tocante a si los profetas consideraron la creación u otro evento como histórico o incluso si lo usaron solamente por propósitos literarios o teológicos, no puede sostenerse en base a los datos textuales e incluso podría proyectarse a un debatido siglo XIX racionalista dentro del contexto de un primer milenio AC en el cual no hubiera existido de otro modo.

${ }^{99}$ Rendtorff, “Some Reflections on Creation”, 207. 